\title{
La desigualdad en México a partir de un modelo estadístico idealizado de demandas Marshallianas, 2012-2014
}

Inequality in Mexico based on an idealized statistical model of Marshallian

demands, 2012-2014

\section{Ximena Valentina Echenique Romero *}

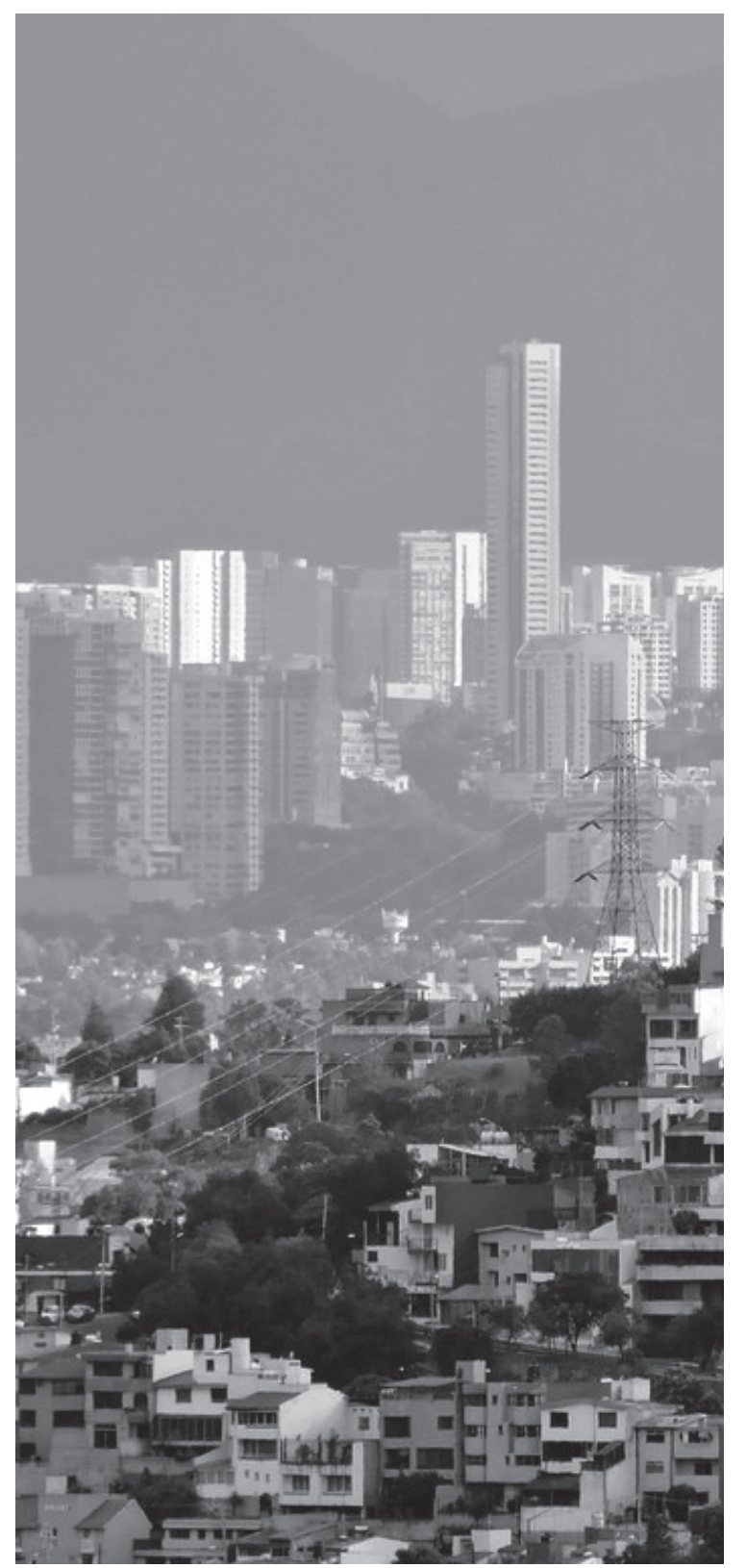

* Académica de la Facultad de EconomíaUNAM en el Departamento de Teoría Económica. Candidata del Sistema de Nacional de Investigadores a partir de 2015. Estudios de Posgrado en el Instituto Tecnológico Autónomo de México y Facultad de Economía-UNAM

Palabras clave

Desigualdad, Bienestar general, Modelización econométrica

Key words Inequality, General Wellfare, Econometric modeling

JEL D63, I31, C5 


\section{Ximena Valentina Echenique Romero |}

La desigualdad en México a partir de un modelo estadístico

idealizado de demandas Marshallianas, 2012-2014

\section{Resumen}

Este texto realiza un análisis cuantitativo sobre la desigualdad en México entre 2012 y 2014. La investigación establece un vinculo entre la Economía Política Liberal y la Teoría Económica Ortodoxa a partir del estudio de la desigualdad. Primero, el texto indica la relevancia de medir la desigualdad por ser la igualdad el estado al que debería aspirar una sociedad donde impere el valor de la justicia. Segundo, el escrito presenta los resultados de un modelo estadístico económico idealizado de demandas Marshallianas sobre un conjunto de bienes y servicios básicos (leche entera, carne, huevo, pan blanco, agua embotellada, y servicios médicos) en los hogares mexicanos. Finalmente, la investigación concluye que, bajo ciertos supuestos y con excepción de las consultas médicas generales, la reducción sobre las diferencias en el consumo entre los diez deciles de hogares en México está explicada por el descenso del ingreso promedio trimestral a partir del cuarto decil y el aumento de los precios de los bienes y servicios considerados en este estudio. Es decir, si la brecha en el consumo está cerrándose es debido a un ingreso real disminuido. Estas conclusiones invitan a reflexionar sobre la pertinencia de una política económica enfocada a garantizar niveles dignos de empleo, educación, alimentación y vivienda.

\section{Abstract}

This text makes a quantitative analysis on inequality in Mexico between 2012 and 2014. The research establishes a link between Liberal Political Economy and Orthodox Economic Theory from the study of inequality. First, the text indicates the relevance of measuring inequality because the equality is the value that should prevail in a just society. Second, the paper presents the results of an idealized economic statistical model of Marshallian demands on a set of basic goods and services (whole milk, meat, egg, white bread, bottled water, and medical services) in Mexican households. Finally, the investigation concludes that, under certain assumptions and with the exception of general medical consultations, the reduction in consumption differences among the ten deciles of households in Mexico is explained by the decrease in average quarterly income from the fourth decile and the increase of the prices of the goods and services considered in this study. That is, if the gap in consumption is closing is due to a decreased real income. These conclusions invite us to reflect on the relevance of an economic policy focused on guaranteeing decent levels of employment, education, food and housing.

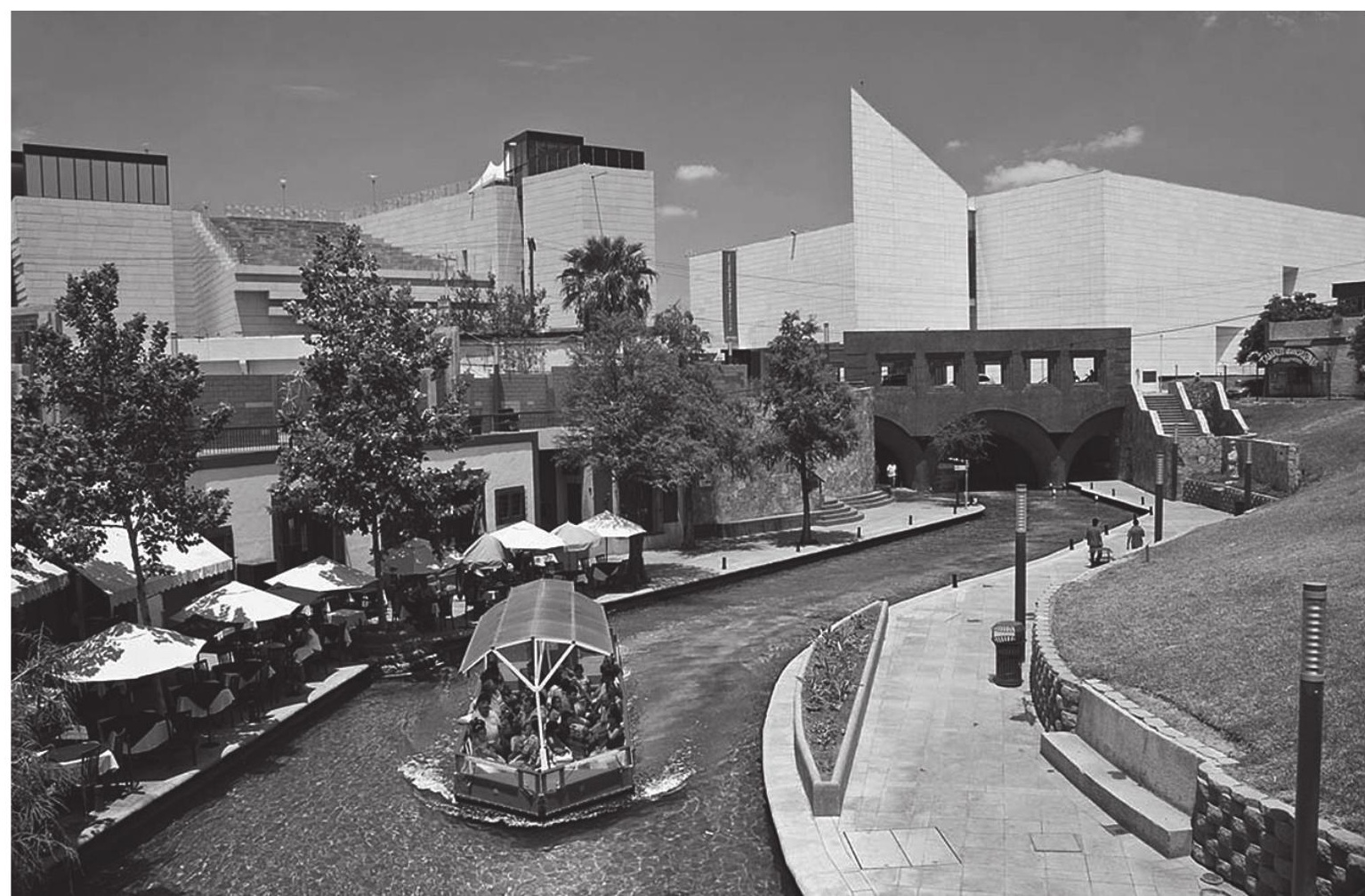




\section{Introducción}

El interés del presente escrito es asociar el aprendizaje de uno de los temas más importantes de un curso universitario de Teoría Económica: las demandas Marshallianas, ${ }^{1}$ con un tema central para la agenda académica no solamente por tratarse de una problemática que no ha cedido en cuanto a sus impactos sociales, sino porque su abordaje ha concitado desacuerdo entre los analistas: la desigualdad.

Aquí proponemos un modelo estadístico económico idealizado (MEEI) que muestra cuál es el panorama que se vive en el país en cuanto a niveles mínimos de bienestar a partir del acceso a leche entera, carne, huevo, pan blanco, agua embotellada, y servicios médicos. Primero, desarrollamos las demandas Marshallianas ${ }^{2}$ que resultan del proceso de optimización de la función de utilidad básica Cobb-Douglas. Segundo, asignamos valores a los parámetros alfa y beta, cuya "arbitrariedad" responde a las posibles elasticidades y preferencias que pueden tener los consumidores sobre dos bienes sustitutos. Por lo que, el valor de estos parámetros resultan estrictas pruebas de hipótesis en un MEEI dirigido a determinar la cantidad demandada de dos bienes sustitutos.

Los hallazgos más importantes de la investigación están relacionados con: 1) la reducción de la desigualdad debido a un descenso de la demanda por una caída del ingreso; 2) el impacto significativo del descenso del ingreso y el aumento de los precios sobre el cuarto

1 La definición de las demandas Marshallianas se encuentra en el segundo apartado del artículo.

2 Las demandas Marshallianas parten de dos supuestos neoclásicos básicos: los seres humanos son completamente racionales y poseen información completa. Supuestos, recientemente, cuestionados por la Economía del Comportamiento. decil de los hogares mexicanos; 3) la profunda desigualdad en la sociedad mexicana con respecto a la cantidad de proteínas animales consumidas y el número de consultas médicas adquiridas. Por lo que, la desigualdad debe estar entre los principales temas de la agenda nacional, junto con el empleo. Temas de investigación que, a partir del Siglo xxI, definen la política económica para el desarrollo.

\section{1.- La relevancia de estimar la desigualdad entre la población mexicana.}

Existe una máxima entre los especialistas en ciencia en datos: "sin definición no hay medición”. Sin embargo, la conceptualización de la desigualdad tiene una fuerte carga moral, ética y política, que podríamos remitirnos a los estudios clásicos de Aristóteles (60 a.c.), Hobbes (1651), Locke (1690) y Rousseau (1755, 1762) para intentar definir esta categoría de análisis. La controversia es la misma para encontrar el significado real de la igualdad.

De acuerdo con los estudios contemporáneos definir la igualdad implica una pregunta: ¿igualdad respecto a qué? Si la respuesta es: igualdad respecto al ingreso, se puede comprender porque para la mayoría de los economistas el tema se ha reducido a un asunto de justicia distributiva.

La teoría neoclásica simplifica el análisis y construye una tesis que, incluso, podría valerse del sentido proporcional de la igualdad planteado por Aristóteles para justificar "moralmente" cualquier desigualdad que se presente en la distribución del ingreso. Porque desde la visión economicista la distribución del ingreso está correlacionada con la remuneración a los factores de producción y el producto marginal de los mismos, en este sentido, la distribución del ingreso conserva el principio proporcional de la igualdad. 
Ximena Valentina Echenique Romero |

La desigualdad en México a partir de un modelo estadístico

idealizado de demandas Marshallianas, 2012-2014.

Entonces, la teoría económica neoclásica aplica teóricamente la "justicia en términos de proporcionalidad: lo que cada persona recibe debe ser proporcional a lo que él o ella contribuye". ${ }^{3}$ Y, de ahí se han derivado conclusiones como si la igualdad consistiera en un consumo per cápita igual para cada ciudadano, "las diferencias en la distribución de los bienes, por ejemplo, serán justificables a través de razones universalmente aceptables". ${ }^{4}$

La tesis de la justicia proporcional y la lotería natural encontraron fuertes argumentos en John Rawls y Ronald Dworkin. Para el primer autor existe una interpretación democrática de la igualdad que combina, por un lado, "la justa igualdad de oportunidades", que está relacionada con establecer perspectivas similares a aquellos con capacidades y habilidades semejantes, y por otro lado, "el principio de la diferencia”, el cual está diseñado para contrarrestar la distribución injusta de los recursos que resulta de los efectos arbitrarios de la lotería natural. De acuerdo con Rawls, se trata de maximizar las expectativas de los menos favorecidos aspirando a un efecto "en cadena" de los beneficios del sector en mejor posición, de tal forma que los bienes básicos estén garantizados para toda la población. En estricto sentido se pretende maximizar las contribuciones marginales de un sector en pro de los menos favorecidos.

El segundo concepto: "el principio de la diferencia", ha sido considerado fuertemente igualitario y débilmente igualitario. Porque plantea una distribución estrictamente igual

3 Deaton, Angus, El Gran Escape Salud, riqueza y los orígenes de la desigualdad, México, Fondo de Cultura Económica, 2015, p. 28

4

Gosepath, Stefan, Equality, en The Stanford Encyclopedia of Philosophy, Edward N. Zalta (ed.), 2011. URL = http://plato.stanford.edu/archives/spr2011/entries/ equality/.p. 9. (aquella que asemeja una línea de $45^{\circ}$ entre la distribución del ingreso de dos clases). Pero, en ocasiones un ligero aumento del ingreso del sector más desfavorecido pudiera ocasionar una gran pérdida sobre el sector medianamente desfavorecido.

Por otra parte, de acuerdo con Dworkin, existen diferentes conceptos sobre la igualdad: el igualitarismo criterial, el igualitarismo utilitario, el igualitarismo del laissez-faire, el igualitarismo del bienestar y el igualitarismo de recursos. ${ }^{5}$ Para este autor, siguiendo el concepto criterial de la igualdad, la igualdad lisa y llana implica que todo el mundo posea la misma riqueza a lo largo de toda su vida. Sin embargo, Dworkin, rechaza una situación en la cual alguien que decide dedicarse al ocio esté en posición de ganar lo mismo que una persona enfocada en trabajar. Según Dworkin, lo importante es establecer condiciones de igualdad para competir en el mercado. Las habilidades y las decisiones correctas son los elementos que determinan las diferencias en el ingreso o el ganador en una competencia. Y éstos son los factores que justifican la desigualdad sobre la distribución del ingreso en un momento dado.

En estricto sentido, de acuerdo con la Teoría de la Justicia, la desigualdad es un problema de justicia proporcional, el cual la Teoría Económica ha reducido a un tema de distribución del ingreso. Donde el análisis de la desigualdad a través del ingreso se refiere al derecho de un nivel mínimo de recursos. Mientras que el estudio de la desigualdad a partir de niveles de consumo se centra en los estándares de vida. ${ }^{6}$

5 Dworkin, Ronald, Justicia para erizos, México, Fondo de Cultura Económica, 2014, pp. 131 y 132.

6 Atkinson, Anthony B, Desigualdad ¿Qué podemos hacer?, México, Fondo de Cultura Económica, 2015, p. 60 
El presente estudio combina las diferencias en el ingreso y el consumo entre los deciles de hogares en México por incorporar los ingresos por deciles y la adquisición de seis bienes y dos servicios de consumo básicos.

\section{2.- Un modelo estadístico económico idealizado para medir la desigualdad en México}

En este artículo la base del calculo de las demandas Marshallianas en México es un modelo estadístico económico idealizado, cuyos supuestos son los de una función de utilidad Cobb Douglas con rendimientos constantes a escala. Los parámetros alfa y beta, que representan las posibles preferencias sobre el consumo de cada bien, determinan la cantidad demandada de dos bienes sustitutos. Recordemos que "la hipótesis Cobb-Douglas es, algunas veces, una buena aproximación para ciertos sub-periodos o sectores y, en cualquier caso, un punto de partida útil para futuras reflexiones".

Mediante un proceso de optimización de la función de utilidad Cobb Douglas calculamos las demandas Marshallianas:

$u(x, y)=x^{\alpha} y^{l-\alpha}$ Función de utilidad. Donde, $1-\alpha=\beta$

$P_{x} x+P_{y} y=W$, Restricción presupuestal.

$\mathcal{L}=\mathrm{x}^{\alpha} \mathrm{y}^{1-\alpha}-\lambda\left(P_{x} x+P_{y} y=W\right)$

$\partial \mathcal{L} / \partial x=\alpha x^{\alpha-1} y^{1-\alpha}-\lambda P_{x}=0$

$\partial \mathcal{L} / \partial y=(1-\alpha) x^{\alpha} y^{-\alpha}-\lambda P_{y}=0$

$\partial \mathcal{L} / \partial \lambda=-P_{x} x-P_{y} y+W=0$

7 Piketty, Thomas, Capital in the Twenty-First Century, Londres, The Belknap Press of Harvard University Press, 2014, p. 218.

$$
\begin{aligned}
& x^{M}\left(P_{x^{\prime}}, P_{y^{\prime}}, W\right)=W / P_{x} \alpha \\
& y^{M}\left(P_{x}, P_{y^{\prime}}, W\right)=W / P_{y}(1-\alpha)
\end{aligned}
$$

De acuerdo con la Ecuación 1.4, la demandada Marshalliana del bien x $\left(x^{M}\right)$ depende directamente del ingreso y el coeficiente $\alpha$, e inversamente de su precio. Igualmente, la demandada Marshalliana del bien y $\left(y^{M}\right)$ depende directamente del ingreso y el coeficiente $\beta$, e inversamente de su precio.

Para el caso de estudio en México calculamos los precios de seis grupos de bienes y dos grupos de servicios. Estos son: 1)leche bolsa de $500 \mathrm{~g}, 2$ )cortes especiales de carne, 3)otros cortes especiales de carne, 4)pan blanco paquete de 680g, 5)agua embotellada de 1.5 litros, 6) huevo blanco paquete de 12 piezas, 7)médico especialista y 8)química sanguínea. Además, recopilamos los datos del ingreso corriente total promedio trimestral por deciles de hogares en México de 2012 y 2014, que reporta la Encuesta Nacional de Ingreso y Gasto de los Hogares (ENIGH) del INEGI.

El Cuadro 1 contiene los precios de los bienes y servicios básicos antes referidos. En este cuadro observamos que, con excepción del huevo Bachoco y las consultas médicas generales, los precios aumentaron entre 2012 y 2014. La Gráfica 1 representa el comportamiento del ingreso trimestral promedio por deciles de hogares. Entre 2012 y 2014, el ingreso descendió a partir del cuarto decil, la reducción más alta estuvo en el octavo decil con una variación promedio anual de $-2.61 \%$. En cambio, el aumento del ingreso más importante estuvo en el segundo decil con una tasa de crecimiento promedio anual de 3.05\%. 


\section{Ximena Valentina Echenique Romero |}

La desigualdad en México a partir de un modelo estadístico

idealizado de demandas Marshallianas, 2012-2014

\section{Cuadro 1}

Precios promedio a nivel nacional de la leche, carne, pan, huevo, y servicios médicos, 2012-2014 ¹/

\begin{tabular}{llll}
\hline & \multicolumn{1}{c}{ Descripción del bien ${ }^{2 /}$} & $\mathbf{2 0 1 2}$ & $\mathbf{2 0 1 4}$ \\
\hline Precio del bien $x$, grupo uno & Alpura, entera, bolsa de $500 \mathrm{~g}$ & $\$ 90.70$ & $\$ 93.68$ \\
Precio del bien y, grupo uno & Fortileche, entera, bolsa de $500 \mathrm{~g}$ & $\$ 72.19$ & $\$ 75.45$ \\
Precio del bien $x$, grupo dos & Cortes especiales, Sirloin, a granel & $\$ 107.41$ & $\$ 127.07$ \\
Precio del bien y, grupo dos & Cortes especiales, filete en medallones, a granel & $\$ 250.38$ & $\$ 285.63$ \\
Precio del bien $x$, grupo tres & Cortes especiales, filete limpio, a granel & $\$ 265.88$ & $\$ 299.27$ \\
Precio del bien y, grupo tres & Bistec, bola, a granel & $\$ 96.50$ & $\$ 117.67$ \\
Precio del bien $x$, grupo cuatro & Bimbo, blanco, paq. de 680 g & $\$ 35.05$ & $\$ 38.53$ \\
Precio del bien y, grupo cuatro & Wonder, blanco, paq de 680 g & $\$ 34.53$ & $\$ 43.86$ \\
Precio del bien $x$, grupo cinco & Ciel, natural, botella de 1.5 I & $\$ 5.95$ & $\$ 6.58$ \\
Precio del bien y, grupo cinco & Bonafont, natural, botella de 1.5 I & $\$ 5.99$ & $\$ 7.39$ \\
Precio del bien $x$, grupo seis & Bachoco, blanco, paq. de 12 pzas. & $\$ 27.78$ & $\$ 21.75$ \\
Precio del bien y, grupo seis & San juan, blanco, paq. de 12 pzas. & $\$ 25.83$ & $\$ 26.60$ \\
Precio del bien $x$, grupo siete & Especialista, medico general, consulta & $\$ 350.00$ & $\$ 167.5$ \\
Precio del bien y, grupo siete & Especialista, medico general, consulta primera vez & $\$ 211.11$ & $\$ 258.21$ \\
Precio del bien $x$, grupo ocho & Química sanguínea, completa & $\$ 250.00$ & $\$ 367.00$ \\
Precio del bien y, grupo ocho & Química sanguínea, 6 elementos & $\$ 227.67$ & $\$ 287.95$ \\
\hline
\end{tabular}

1/ Los precios representan el nivel promedio considerando únicamente las entidades federativas con registros de los precios en cuestión.

2/ La descripción de los bienes respeta en su totalidad la descripción del INEGI

Fuente: elaboración propia con base en http://www.inegi.org.mx/sistemas/indiceprecios/inpc.aspx

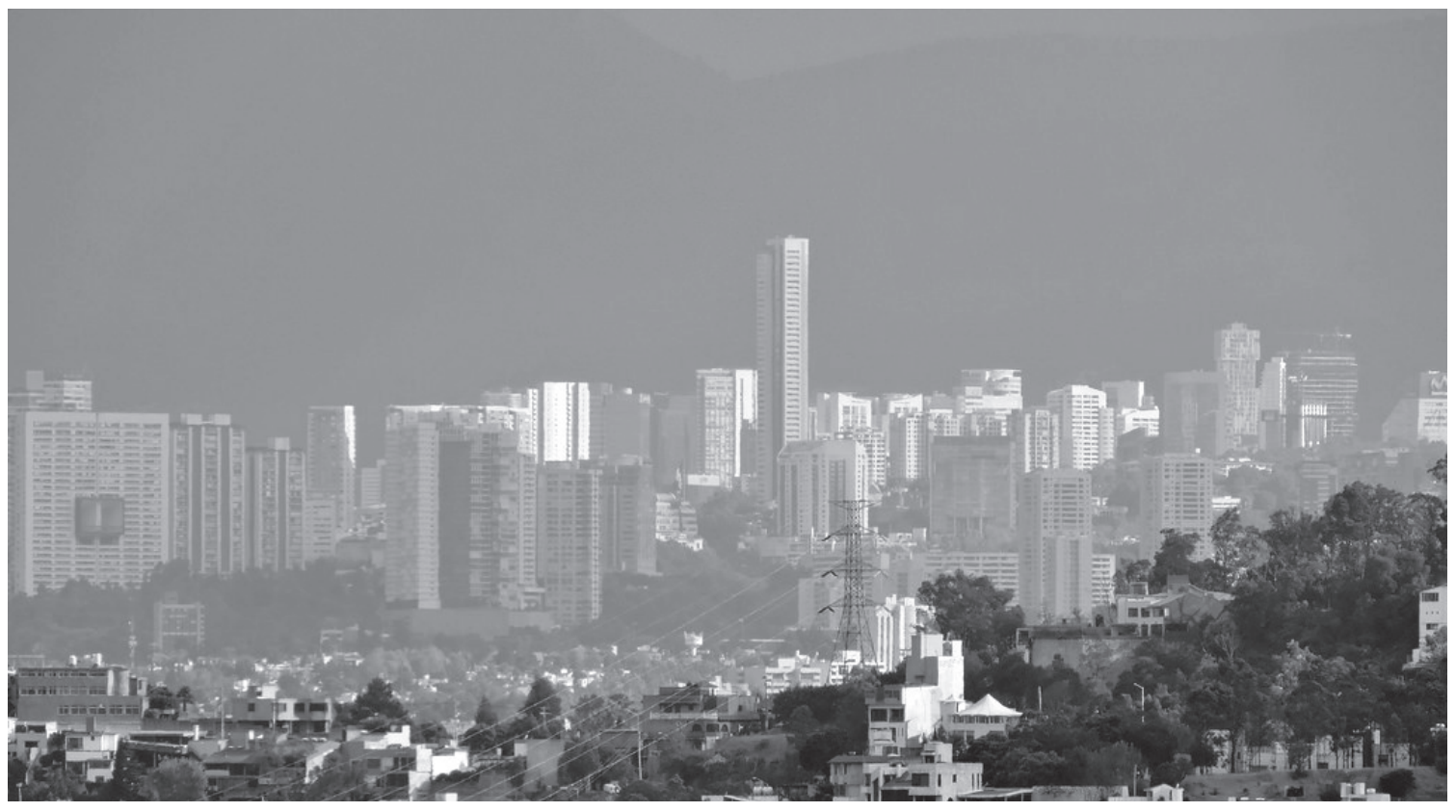

Fuente: Encuesta Nacional de Ingreso y Gasto de los Hogares, ENIGH 2014. INEGI. http://www.inegi.org.mx/est/contenidos/proyectos/encuestas/hogares/regulares/enigh/enigh2014/tradicional/doc/resultados_enigh14.pdf 
Es importante aclarar que la fuente estadística principal de nuestros indicadores: la ENIGH, ha sido fuertemente cuestionada, ${ }^{8}$ junto con la propia metodología de las encuestas de ingresos en otros países. ${ }^{9}$ Sin embargo, esto no invalida las estimaciones de nuestro estudio. Porque, como menciona Angus Deaton: las "medidas globales de pobreza y desigualdad están preñadas de dificultades". ${ }^{10} \mathrm{Y}$, si bien "nuestras medidas de la pobreza y la desigualdad son solo tan buenas como nuestras medidas del ingreso"," también es cierto que, incluso, "si consideramos el consumo en lugar del ingreso, entonces los hallazgos respecto de la desigualdad y la pobreza pueden ser diferentes". ${ }^{12}$

\section{3.- La desigualdad en México a partir de las demandas Marshallianas}

De acuerdo con los datos presentados en el Cuadro 1 y la Gráfica 1, nos propusimos calcular las demandas Marshallianas para México. Por ejemplo, considerando el ingreso trimestral promedio del primer decil de hogares en México y una función de utilidad con rendimientos constantes a escala con parámetros $\alpha$ y $\beta$ de 0.5 (suponiendo que las preferencias por ambos bienes son equitativas), para el primer grupo de bienes: bolsa de leche Alpura de 500g. (bien x) y bolsa de leche Fortileche de 500g. (bien y), el calculo es el siguiente en 2012:

Demanda de Leche Alpura, $x^{M}\left(P_{x}, P, W\right)=$ $W / P_{x} a=4568 / 90.70^{*} 1 / 2=25.18$,

8 Véase Del Castillo, Miguel, La magnitud de la desigualdad en el ingreso y la riqueza en México, Serie Estudios y Perspectivas Núm. 167, México, CEPAL, 2015, pp- 15$58,79-81$

9 Véase Atkinson, Anthony B, op. cit. pp. 78-84

10 Deaton, Angus, op. cit. pp. 50

11 Ibídem. Véase Boltvinik, Julio, Pobreza y distribución del ingreso en México, México, Siglo xxı editores, 4 ed, 2006.

12 Atkinson, Anthony B, Op. Cit. p.58
Demanda de Leche Fortileche, $y^{M}\left(P_{x}, P, W\right)$ $=W / P_{y}(1-a)=4568 / 72.19^{*} 1 / 2=31.64$,

En siguiente sección describimos el comportamiento de las demandas Marshallianas en México sobre los ochos grupos de análisis. Los valores de los parámetros en la función de utilidad Cobb Douglas, que son: $u(x, y)=x^{1 / 2} y^{1 / 2}$, $u(x, y)=x^{1 / 3} y^{1-1 / 3}, y, u(x, y)=x^{2 / 3} y^{1-2 / 3}$, determinan la cantidad demandada según las distintas posibles preferencias de los consumidores, que también representan pruebas de hipótesis sobre las elasticidades de cada bien sustituto.

\subsection{Las demandas Marshallianas de bienes básicos en México}

Respecto al primer grupo de análisis de nuestra muestra (Leche) suponiendo que la totalidad del ingreso promedio trimestral por decil de hogares hubiera sido gastado en leche, entonces, el número de paquetes de leche Alpura consumidos por el primer decil habrían sido: 17 en la primera función de utilidad $\left(u(x, y)=x^{1 / 3} y^{2 / 3}\right), 34$ en la segunda función de utilidad $\left(u(x, y)=x^{2 / 3} y^{1 / 3}\right)$, y 25 en la tercera función de utilidad $\left(u(x, y)=x^{1 / 2} y^{1 / 2}\right)$ durante 2012 y 2014.

En 2012 y 2014, estas cifras de consumo de leche Alpura sumarían por año para el segundo decil: 30 y $31\left(u(x, y)=x^{1 / 3} y^{2 / 3}\right), 61$ y 63 $\left(u(x, y)=x^{2 / 3} y^{1 / 3}\right), y, 46$ y $47\left(u(x, y)=x^{1 / 2} y^{1 / 2}\right)$, respectivamente. Para el tercer decil: 44 y 43,88 y 86, y, 66 y 65. Para el cuarto decil: 56 y 54, 111 y 107, y, 84 y 81.Para el quinto decil: 71 y 67, 143 y 134, y, 107 y 100. Para el sexto decil: 86 y 81, 171 y 162, y, 128 y 121.Para el séptimo decil: 107 y 102, 214 y 204, y, 161 y 153. Para el octavo decil: 140 y 129, 281 y 257, y, 210 y 193. Para el noveno decil: 195 y 181, 390 y 363, y, 293 y 272. Para el decimo decil: 442 y 420, 883 y 840, y, 662 y 630. (Ver Cuadro 2) 
Ximena Valentina Echenique Romero |

La desigualdad en México a partir de un modelo estadístico

idealizado de demandas Marshallianas, 2012-2014

Cuadro 2

Demandas Marshallianas de paquetes de leche (500g.) en México, 2012-2014. ${ }^{1}$

\begin{tabular}{|c|c|c|c|c|c|c|c|c|c|c|c|c|}
\hline & \multicolumn{4}{|c|}{$u: x^{1 / 3} y^{2 / 3}$} & \multicolumn{4}{|c|}{$u: x^{2 / 3} y^{1 / 3}$} & \multicolumn{4}{|c|}{$u: x^{1 / 2} y^{1 / 2}$} \\
\hline & \multicolumn{2}{|c|}{2012} & \multicolumn{2}{|c|}{2014} & \multicolumn{2}{|c|}{2012} & \multicolumn{2}{|c|}{2014} & \multicolumn{2}{|c|}{2012} & \multicolumn{2}{|c|}{2014} \\
\hline & $x$ & $y$ & $\mathbf{x}$ & $y$ & $\mathbf{x}$ & $y$ & $x$ & $y$ & $x$ & $y$ & $x$ & y \\
\hline I & 17 & 42 & 17 & 42 & 34 & 21 & 34 & 21 & 25 & 32 & 25 & 31 \\
\hline II & 30 & 77 & 31 & 78 & 61 & 38 & 63 & 39 & 46 & 57 & 47 & 58 \\
\hline III & 44 & 111 & 43 & 107 & 88 & 55 & 86 & 54 & 66 & 83 & 65 & 80 \\
\hline IV & 56 & 140 & 54 & 133 & 111 & 70 & 107 & 67 & 84 & 105 & 81 & 100 \\
\hline $\mathbf{V}$ & 71 & 179 & 67 & 166 & 143 & 90 & 134 & 83 & 107 & 134 & 100 & 124 \\
\hline VI & 86 & 215 & 81 & 201 & 171 & 107 & 162 & 100 & 128 & 161 & 121 & 150 \\
\hline VII & 107 & 269 & 102 & 253 & 214 & 135 & 204 & 126 & 161 & 202 & 153 & 189 \\
\hline VIII & 140 & 352 & 129 & 320 & 281 & 176 & 257 & 160 & 210 & 264 & 193 & 240 \\
\hline IX & 195 & 490 & 181 & 450 & 390 & 245 & 363 & 225 & 293 & 368 & 272 & 338 \\
\hline $\mathbf{x}$ & 442 & 1,110 & 420 & 1,043 & 883 & 555 & 840 & 522 & 662 & 832 & 630 & 782 \\
\hline
\end{tabular}

${ }^{1} \mathrm{x}$ : Leche Alpura (500g.), y: Leche Fortileche (500g.)

Fuente: Encuesta Nacional de Ingreso y Gasto de los Hogares, ENIGH 2014. INEGI.

http://www.inegi.org.mx/est/contenidos/proyectos/encuestas/hogares/regulares/enigh/enigh2014/tradicional/ doc/resultados_enigh14.pdf

http://www.inegi.org.mx/sistemas/indiceprecios/inpc.aspx

El comportamiento anterior se repite para la leche Fortileche. Esto es, el primer y el segundo decil de hogares consumirían más unidades de leche del 2012 al 2014. Y, a partir del tercer decil el número de unidades consumidas de leche Fortileche disminuiría. Aunque, la desigualdad en el consumo continuaría presente entre los deciles de hogares mexicanos.

Entre las funciones de utilidad analizadas fue la función $\left(u(x, y)=x^{1 / 3} y^{2 / 3}\right)$ la que determinó la mayor desigualdad en el consumo de leche. En 2012, según esta función existió una brecha en el consumo entre el primer y el decimo decil de 425 paquetes de leche Alpura y 1068 de leche Fortileche. Mientras que, en 2014, esta diferencia de consumo fue de 403 y 1001 , respectivamente.

Los resultados anteriores estuvieron relacionados con la tasa de crecimiento promedio anual (TСРA) de la demanda, la elasticidad pre- cio de la demanda $\left(\varepsilon_{p}^{d}\right)$ y la elasticidad ingreso de la demanda $\left(\varepsilon_{y} d\right)^{p}{ }^{13}$ Entre 2012 y 2014, la demanda de leche Alpura y de leche Fortileche disminuyó desde el tercer decil. La caída más importante en el consumo de ambos productos sucedió en el quinto y el octavo deciles. La variación de la demanda de leche Fortileche en el $\mathrm{V}$ decil fue de $-3.22 \%$ y en el viII decil de $-4.66 \%$ (Gráfica 2). Además, la inflación promedio anual de la leche Fortileche fue de $2.26 \%$ y la inflación promedio anual de la leche Alpura de 1.64\%. Dos valores que, junto con el desempeńo del ingreso trimestral pro-

13 La elasticidad ingreso de la demanda $\left(\varepsilon_{y}^{d}\right)$ estima la variación porcentual de la cantidad demandada sobre la variación porcentual del ingreso. La elasticidad precio de la demanda $\left(\varepsilon_{p}{ }^{d}\right)$ estima la variación porcentual de la cantidad demandada sobre la variación porcentual del precio. El calculo de la $\varepsilon_{p}{ }^{d}$ y la $\varepsilon_{y}{ }^{d}$ se realizaron con la función $u(x, y)=x^{1 / 2} y^{1 / 2}$ con la finalidad de realizar una estimación homogénea y neutral sobre los dos bienes sustitutos. 
medio, determinaron las siguientes elasticidades del precio de la demanda. Una $\varepsilon_{p}{ }^{d}$ positiva ${ }^{14}$ de la leche Alpura en el segundo decil de los hogares mexicanos. Una $\varepsilon_{p}{ }^{d}$ negativa ${ }^{15}$ desde el tercer decil (Gráfica 3). Finalmente, la $\varepsilon_{y}{ }^{d}$ fue positiva $^{16}$ a partir del tercer decil y, particularmente, significativa en el cuarto decil (Gráfica 4). Hecho que confirmaría el efecto de la caída del ingreso trimestral promedio desde el cuarto decil.
Respecto al segundo grupo de análisis de nuestra muestra (Sirloin y Medallones) suponiendo que la totalidad del ingreso promedio trimestral por decil de hogares hubiera sido gastado en cortes especiales de carne en 2012 y 2014, el número de cortes de Sirloin consumidos por el primer decil habrían sido: 14 y 12 en la primera función de utilidad $\left(u(x, y)=x^{1 / 3} y^{2 / 3}\right)$, 28 y 25 en la segunda función de utilidad $\left(u(x, y)=x^{2 / 3} y^{1 / 3}\right), y, 21$ y 18 en la tercera función

\section{Gráfica $2 \mathrm{TCPA}^{/ 1}$ de la demanda de leche en México, 2012-2014 ${ }^{12}$}

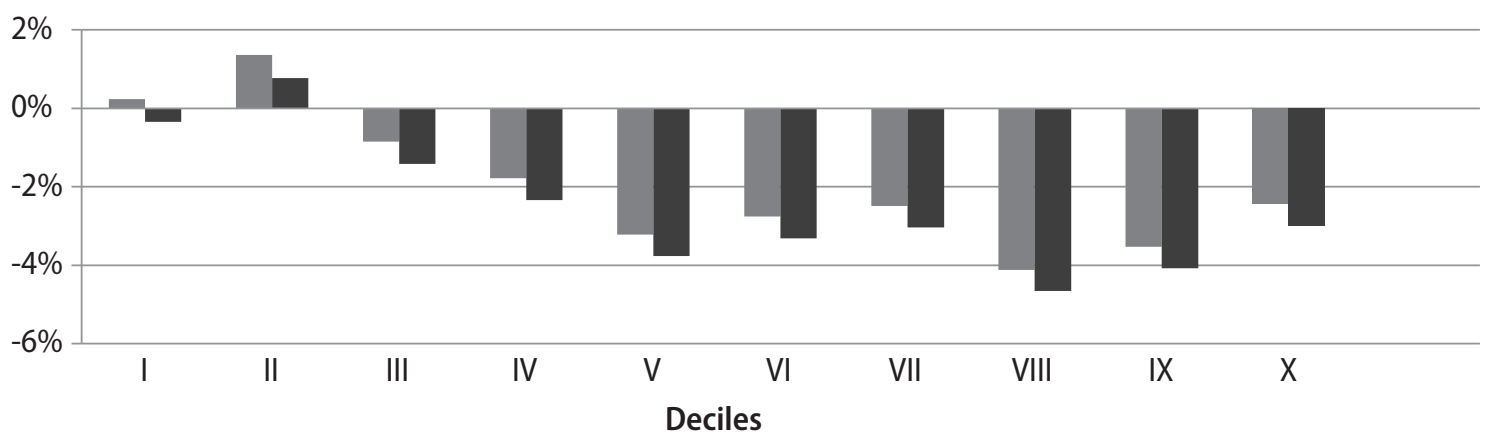

- Leche Alpura, bolsa 500g. — Leche Fortileche, bolsa $500 \mathrm{~g}$.

${ }^{1}$ Tasa de Crecimiento Promedio Anual, TCPA

${ }^{2}$ Demanda de acuerdo con la función de utilidad $u=x^{1 / 2} y^{1 / 2}$

Fuente: elaboración propia con base en http://www.inegi.org.mx/sistemas/indiceprecios/inpc.aspx

14 En este caso, la elasticidad precio de la demanda fue positiva como resultado de la razón entre una variación porcentual positiva de la cantidad demandada y una variación porcentual positiva del precio.

15 En este caso, la elasticidad precio de la demanda fue negativa como resultado de la razón entre una variación porcentual negativa de la cantidad demandada y una variación porcentual positiva del precio.

16 En este caso, la elasticidad ingreso de la demanda fue positiva como resultado de la razón entre una variación porcentual negativa de la cantidad demandada y una variación porcentual negativa del ingreso. de utilidad $\left(u(x, y)=x^{1 / 2} y^{1 / 2}\right)$. El comportamiento anterior de reducción de consumo se presentaría en todos los deciles. Y, también, la demanda de Medallones disminuiría en los diez deciles de hogares mexicanos.

Entre las funciones de utilidad analizadas fue la función $\left(u(x, y)=x^{2 / 3} y^{1 / 3}\right)$ la que determinó la mayor desigualdad en el consumo de cortes especiales de carne. En 2012, según esta función existió una brecha en el consu- 
Ximena Valentina Echenique Romero |

La desigualdad en México a partir de un modelo estadístico

idealizado de demandas Marshallianas, 2012-2014

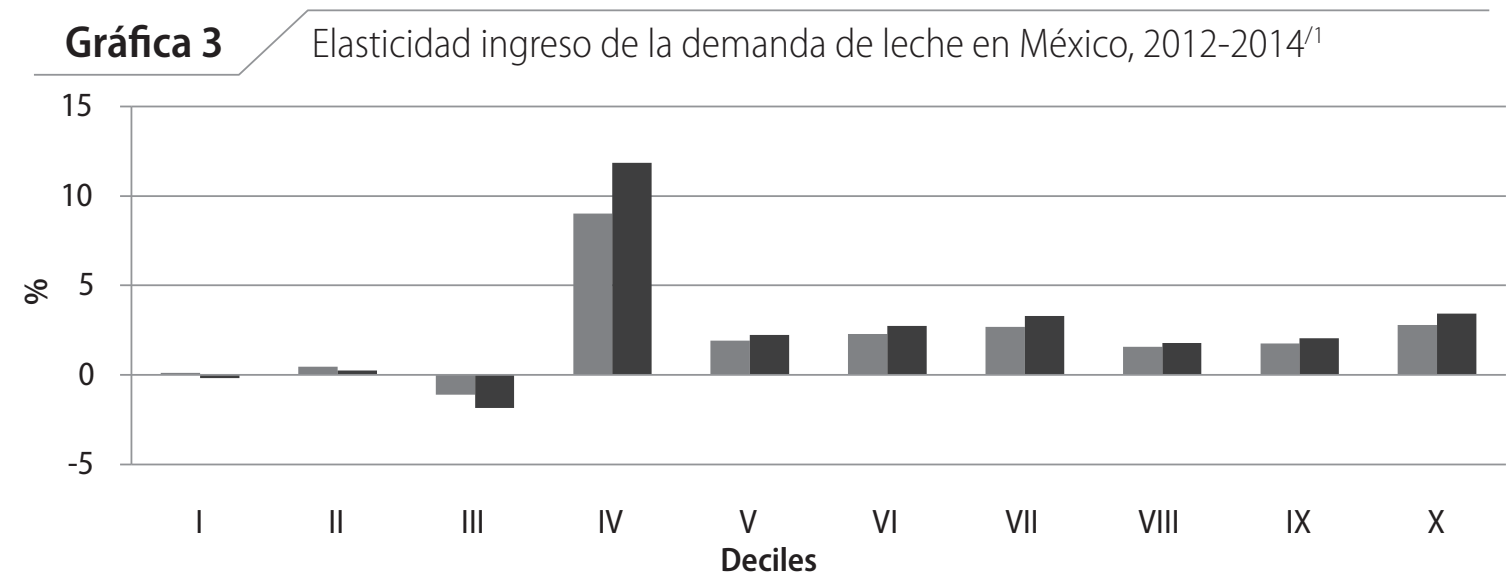

- Elasticidad ingreso de la demanda de Leche Alpura, bolsa 500g.

- Elasticidad ingreso de la demanda de Leche Fortileche,bolsa $500 \mathrm{~g}$.

${ }^{1}$ Demanda de acuerdo con la función de utilidad $u=x^{1 / 2} y^{1 / 2}$

Fuente: elaboración propia con base en http://www.inegi.org.mx/sistemas/indiceprecios/inpc.aspx

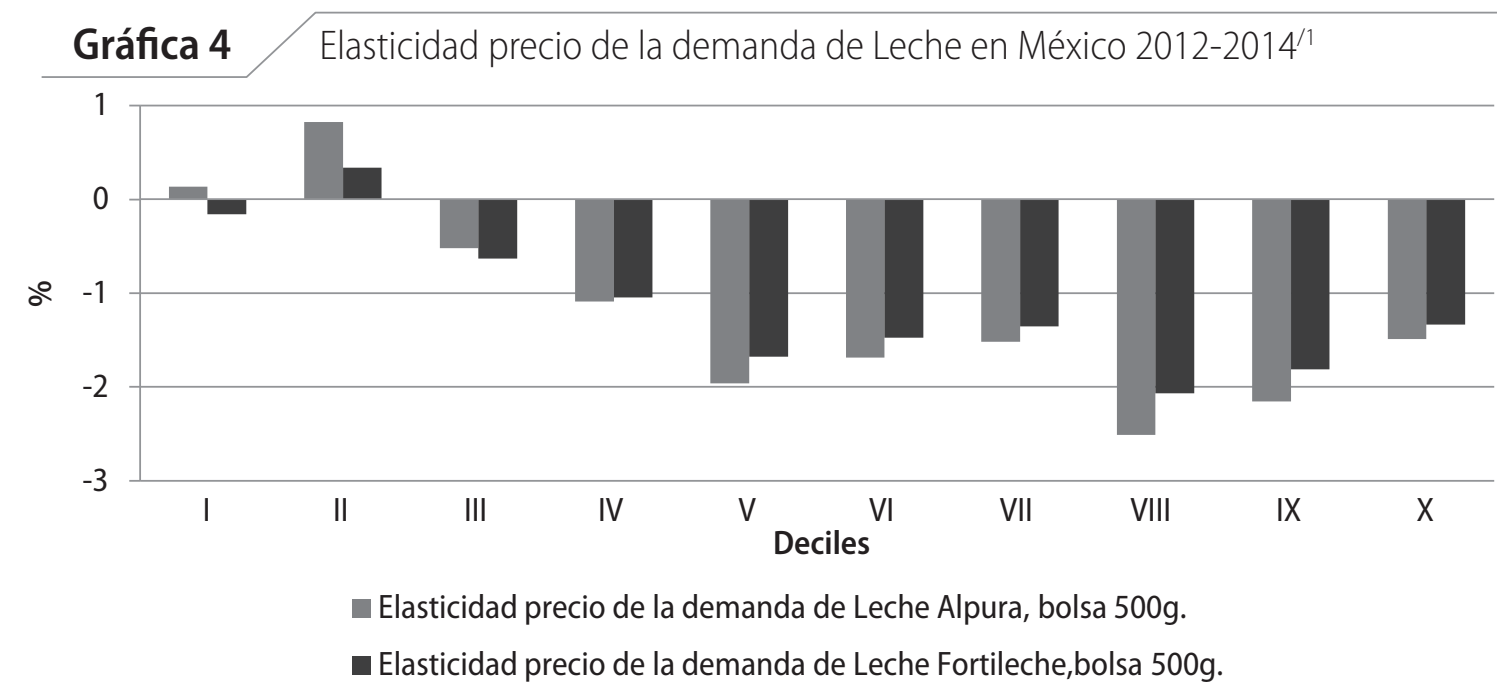

${ }^{1}$ Demanda de acuerdo con la función de utilidad $u=x^{1 / 2} y^{1 / 2}$

Fuente: elaboración propia con base en http://www.inegi.org.mx/sistemas/indiceprecios/inpc.aspx

mo entre el primer y el decimo deciles de 717 cortes de Sirloin y 154 cortes de Medallones. Mientras que, en 2014, esta diferencia de consumo fue de 594 y 132, respectivamente (Cuadro 3).

Entre 2012 y 2014, la caída más importante en el consumo de ambos productos sucedió en el cuarto y el octavo deciles. La va- riación de la demanda de Sirloin en el IV decil fue de $-7.93 \%$ y en el VIII decil de $-9.95 \%$. La variación de la demanda de Medallones en el IV decil fue de $-6.32 \%$ y en el VIII decil de $-8.45 \%$. Estos descensos estuvieron vinculados al aumento del precio promedio de estos dos bienes: $7.04 \%$ en Medallones y $9.15 \%$ en Sirloin. 
Cuadro 3

Demandas Marshallianas de cortes especiales de carne en México, 2012-20141

\begin{tabular}{|c|c|c|c|c|c|c|c|c|c|c|c|c|}
\hline & \multicolumn{4}{|c|}{$u: x^{1 / 3} y^{2 / 3}$} & \multicolumn{4}{|c|}{$u: x^{2 / 3} y^{1 / 3}$} & \multicolumn{4}{|c|}{$u: x^{1 / 2} y^{1 / 2}$} \\
\hline & \multicolumn{2}{|c|}{2012} & \multicolumn{2}{|c|}{2014} & \multicolumn{2}{|c|}{2012} & \multicolumn{2}{|c|}{2014} & \multicolumn{2}{|c|}{2012} & \multicolumn{2}{|c|}{2014} \\
\hline & $x$ & $y$ & $x$ & $y$ & $\mathbf{x}$ & $y$ & $x$ & $y$ & $\mathbf{x}$ & $y$ & $\mathbf{x}$ & $y$ \\
\hline I & 14 & 12 & 12 & 11 & 28 & 6 & 25 & 6 & 21 & 9 & 18 & 8 \\
\hline II & 26 & 22 & 23 & 21 & 51 & 11 & 46 & 10 & 38 & 17 & 34 & 16 \\
\hline III & 37 & 32 & 32 & 28 & 74 & 16 & 64 & 14 & 55 & 24 & 47 & 21 \\
\hline IV & 47 & 40 & 40 & 35 & 94 & 20 & 79 & 18 & 70 & 30 & 59 & 27 \\
\hline v & 60 & 52 & 49 & 44 & 121 & 26 & 98 & 22 & 90 & 39 & 74 & 33 \\
\hline VI & 72 & 62 & 60 & 53 & 144 & 31 & 119 & 27 & 108 & 47 & 89 & 40 \\
\hline VII & 90 & 78 & 75 & 67 & 181 & 39 & 150 & 33 & 135 & 58 & 112 & 50 \\
\hline VIII & 118 & 102 & 95 & 84 & 237 & 51 & 190 & 42 & 177 & 76 & 142 & 63 \\
\hline IX & 165 & 141 & 134 & 119 & 329 & 71 & 267 & 59 & 247 & 106 & 200 & 89 \\
\hline$x$ & 373 & 320 & 310 & 276 & 746 & 160 & 619 & 138 & 559 & 240 & 464 & 207 \\
\hline
\end{tabular}

${ }^{1} \mathrm{x}$ : Sirloin, , y: Medallones

Fuente: Encuesta Nacional de Ingreso y Gasto de los Hogares, ENIGH 2014. INEGI.

http://www.inegi.org.mx/est/contenidos/proyectos/encuestas/hogares/regulares/enigh/enigh2014/tradicional/ doc/resultados_enigh14.pdf

http://www.inegi.org.mx/sistemas/indiceprecios/inpc.aspx

El crecimiento del ingreso que presentaron los tres primeros deciles de hogares no impulsó el consumo de los cortes de carne. En términos de la $\varepsilon_{Y}{ }^{D}$, el cuarto decil fue el más afectado por su contracción del ingreso promedio de $0.77 \%$ entre 2012 y 2014 . En este decil la $\varepsilon_{Y}{ }^{D}$ del Sirlon fue de $40 \%$ y del filete en Medallones de $32 \%$.

Por otra parte, el tercer, cuarto, sexto, octavo y noveno grupo de análisis comparten el comportamiento del segundo grupo de análisis porque el consumo descendió en todos los deciles. Pero, también presenta las siguientes particularidades:

Respecto al tercer grupo de análisis de nuestra muestra (Filete limpio y Bistec bola)

*La función $\left(u(x, y)=x^{1 / 3} y^{2 / 3}\right)$ estableció la mayor desigualdad en el consumo de otros cortes especiales de carne. En 2012, según esta función existió una brecha en el consumo entre el primer y el decimo decil de 145 cortes de Filete limpio y 799 cortes de Bistec bola. Mientras que, en 2014, esta diferencia de consumo fue de 126 y 642 respectivamente. (Cuadro 4)

* Entre 2012 y 2014, la caída más importante en el consumo sucedió en el Bistec en bola en el quinto y el octavo decil. La variación de la demanda en el V decil fue de $-10.40 \%$ y en el VIII decil de - $11.15 \%$. La inflación promedio anual más alta se presentó en este corte de carne con $10.97 \%$. Hecho que explicó la pronunciada caída del consumo en este producto respecto al Filete limpio, que alcanzó una inflación de 6.28\%. (Gráfica 5) 
Ximena Valentina Echenique Romero |

La desigualdad en México a partir de un modelo estadístico

idealizado de demandas Marshallianas, 2012-2014

Cuadro 4

Demandas Marshallianas de cortes especiales de carne a granel en México, 2012-20141

\begin{tabular}{|c|c|c|c|c|c|c|c|c|c|c|c|c|}
\hline & \multicolumn{4}{|c|}{$u: x^{1 / 3} y^{2 / 3}$} & \multicolumn{4}{|c|}{$u: x^{2 / 3} y^{1 / 3}$} & \multicolumn{4}{|c|}{$u: x^{1 / 2} y^{1 / 2}$} \\
\hline & \multicolumn{2}{|c|}{2012} & \multicolumn{2}{|c|}{2014} & \multicolumn{2}{|c|}{2012} & \multicolumn{2}{|c|}{2014} & \multicolumn{2}{|c|}{2012} & \multicolumn{2}{|c|}{2014} \\
\hline & $\mathbf{x}$ & $y$ & $\mathbf{x}$ & $y$ & $\mathbf{x}$ & $y$ & $\mathbf{x}$ & $y$ & $\mathbf{x}$ & $y$ & $x$ & $y$ \\
\hline I & 6 & 32 & 5 & 27 & 11 & 16 & 11 & 13 & 9 & 23 & 8 & 20 \\
\hline II & 10 & 57 & 10 & 50 & 21 & 29 & 20 & 25 & 16 & 43 & 15 & 37 \\
\hline III & 15 & 83 & 14 & 69 & 30 & 41 & 27 & 34 & 23 & 62 & 20 & 51 \\
\hline IV & 19 & 105 & 17 & 85 & 38 & 52 & 34 & 43 & 29 & 78 & 25 & 64 \\
\hline V & 24 & 134 & 21 & 106 & 49 & 67 & 42 & 53 & 37 & 100 & 32 & 79 \\
\hline VI & 29 & 161 & 25 & 129 & 58 & 80 & 51 & 64 & 44 & 120 & 38 & 96 \\
\hline VII & 37 & 201 & 32 & 162 & 73 & 101 & 64 & 81 & 55 & 151 & 48 & 121 \\
\hline VIII & 48 & 264 & 40 & 205 & 96 & 132 & 81 & 102 & 72 & 197 & 61 & 153 \\
\hline IX & 67 & 367 & 57 & 289 & 133 & 183 & 114 & 144 & 100 & 275 & 85 & 216 \\
\hline$x$ & 151 & 830 & 131 & 669 & 301 & 415 & 263 & 334 & 226 & 622 & 197 & 501 \\
\hline
\end{tabular}

$1 \mathrm{x}$ : Filete limpio, y: Bistec bola

Fuente: Ibídem

Gráfica 5 TCPA de la demanda de cortes especiales de carne en México, 2012-2014/1

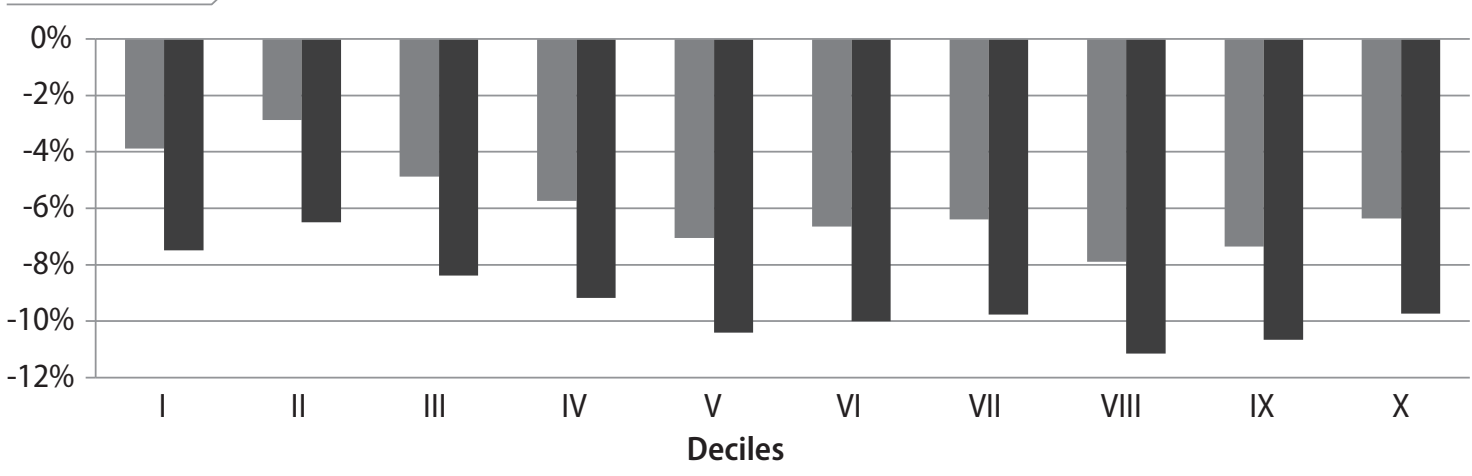

Filete limpio. $\quad$ Bistec bola a granel.

${ }^{1}$ Demanda de acuerdo con la función de utilidad $u=x^{1 / 2} y^{1 / 2}$

Fuente: elaboración propia con base en http://www.inegi.org.mx/sistemas/indiceprecios/inpc.aspx

* En términos de la $\varepsilon_{Y}{ }^{D}$ el cuarto decil fue el más afectado con una $\varepsilon_{Y}{ }^{D}$ de $28.94 \%$ para el Filete limpio y una $\varepsilon_{Y}{ }^{D}$ de $46.30 \%$ para el Bistec en bola.

Respecto al cuarto grupo de análisis de nuestra muestra (Pan Bimbo y Pan Wonder)

* La función $\left(u(x, y)=x^{2 / 3} y^{1 / 3}\right)$ determinó la mayor desigualdad en el consumo de paquetes de pan de 500g. En 2012, según esta función existió una brecha en el consumo entre el primer y el decimo decil de 2199 paquetes de pan Bimbo y 1116 paquetes de pan Wonder. Mientras que, en 2014, esta diferencia de consumo fue de 1961 y 861, respectivamente. (Cuadro 5) 
Cuadro 5

Demandas Marshallianas de pan blanco en México, 2012- 20141

\begin{tabular}{|c|c|c|c|c|c|c|c|c|c|c|c|c|}
\hline & \multicolumn{4}{|c|}{$u: x^{1 / 3} y^{2 / 3}$} & \multicolumn{4}{|c|}{$u: x^{2 / 3} y^{1 / 3}$} & \multicolumn{4}{|c|}{$u: x^{1 / 2} y^{1 / 2}$} \\
\hline & \multicolumn{2}{|c|}{2012} & \multicolumn{2}{|c|}{2014} & \multicolumn{2}{|c|}{2012} & \multicolumn{2}{|c|}{2014} & \multicolumn{2}{|c|}{2012} & \multicolumn{2}{|c|}{2014} \\
\hline & $\mathbf{x}$ & $y$ & $x$ & $y$ & $x$ & $y$ & $\mathbf{x}$ & $y$ & $x$ & $y$ & $x$ & $y$ \\
\hline I & 43 & 88 & 41 & 72 & 87 & 44 & 82 & 36 & 65 & 66 & 61 & 54 \\
\hline II & 79 & 160 & 76 & 134 & 158 & 80 & 152 & 67 & 118 & 120 & 114 & 100 \\
\hline III & 114 & 231 & 105 & 185 & 228 & 116 & 210 & 92 & 171 & 173 & 158 & 139 \\
\hline IV & 144 & 292 & 130 & 229 & 288 & 146 & 261 & 115 & 216 & 219 & 196 & 172 \\
\hline $\mathbf{V}$ & 185 & 375 & 162 & 285 & 369 & 187 & 325 & 143 & 277 & 281 & 244 & 214 \\
\hline VI & 221 & 449 & 196 & 345 & 443 & 225 & 393 & 173 & 332 & 337 & 295 & 259 \\
\hline VII & 277 & 563 & 247 & 435 & 554 & 281 & 495 & 217 & 416 & 422 & 371 & 326 \\
\hline VIII & 363 & 737 & 313 & 550 & 726 & 368 & 626 & 275 & 545 & 553 & 469 & 412 \\
\hline IX & 505 & 1,025 & 441 & 774 & 1,010 & 513 & 882 & 387 & 757 & 769 & 661 & 581 \\
\hline$x$ & 1,143 & 2,320 & 1,021 & 1,794 & 2,286 & 1,160 & 2,043 & 897 & 1,714 & 1,740 & 1,532 & 1,346 \\
\hline
\end{tabular}

1 x: Pan Bimbo (680g), y: Pan Wonder (680g)

Fuente: Encuesta Nacional de Ingreso y Gasto de los Hogares, ENIGH 2014. INEGI.

http://www.inegi.org.mx/est/contenidos/proyectos/encuestas/hogares/regulares/enigh/enigh2014/tradicional/ doc/resultados_enigh14.pdf

http://www.inegi.org.mx/sistemas/indiceprecios/inpc.aspx

\section{Gráfica 6 Elasticidad precio de la demanda de pan blanco en México, 2012-2014/1}

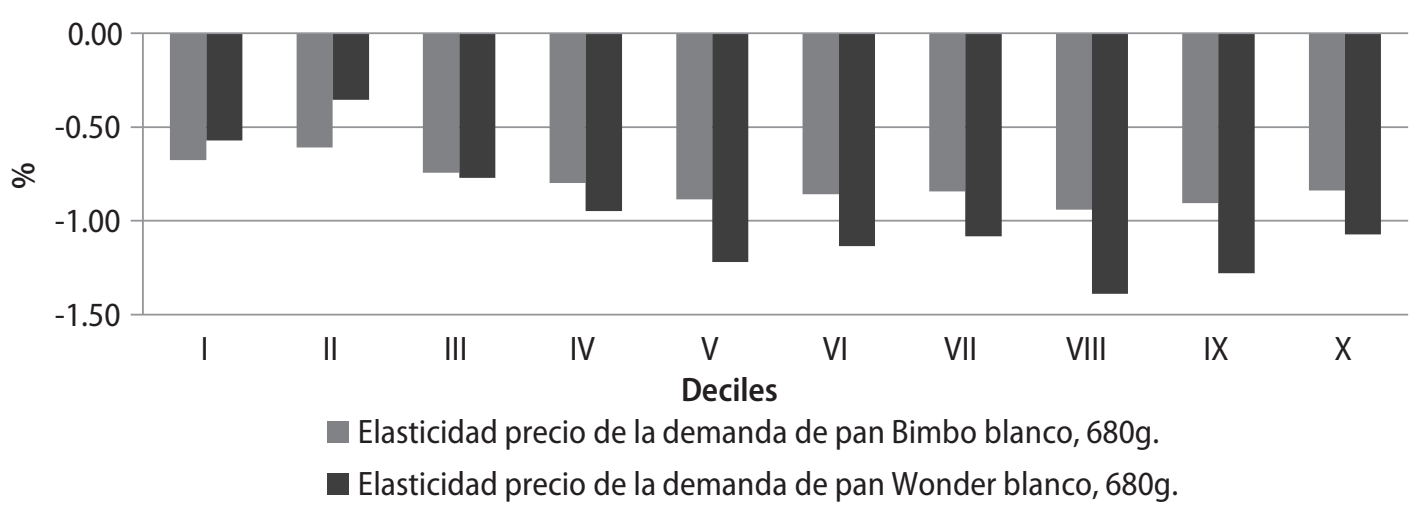

${ }^{1}$ Demanda de acuerdo con la función de utilidad $u=x^{1 / 2} y^{1 / 2}$

Fuente: elaboración propia con base en http://www.inegi.org.mx/sistemas/indiceprecios/inpc.aspx

* Entre 2012 y 2014, el consumo de pan Bimbo y pan Wonder disminuyó en los diez deciles. La caída más importante en el consumo sucedió en el pan Wonder en el quinto y el octavo decil. La variación de la demanda en el $\mathrm{V}$ decil fue de $-11.96 \%$ y en el VIII decil de $-12.69 \%$. La inflación promedio anual más alta se presentó precisamente en el pan Wonder. La TCPA del precio promedio del pan Wonder superó en 9\% el crecimiento del precio del pan Bimbo.

* En términos de la $\varepsilon_{Y}{ }^{D}$, el cuarto decil fue el más afectado con una $\varepsilon_{Y}{ }^{D}$ de $23.75 \%$ para el pan Bimbo y una $\varepsilon_{Y}{ }^{D}$ de $54.45 \%$ para el pan Wonder.

* El octavo decil destacó por una $\varepsilon_{P}{ }^{D}$ de -1.39 en el pan Bimbo. (Gráfica 6) 
Ximena Valentina Echenique Romero |

La desigualdad en México a partir de un modelo estadístico

idealizado de demandas Marshallianas, 2012-2014.

Respecto al sexto grupo de análisis de nuestra muestra (Huevo Bachoco y Huevo San Juan)

${ }^{*}$ La función $\left(u(x, y)=x^{1 / 3} y^{2 / 3}\right)$ determinó la mayor desigualdad en el consumo de paquetes de huevo de 12 piezas. En 2012, según esta función existió una brecha en el consumo entre el primer y el decimo decil de 1691 paquetes de huevo Bachoco y 353 paquetes de huevo San Juan. Mientras que, en 2014, esta diferencia de consumo fue de 1462 y 2 840, respectivamente. (Cuadro 6)
* Entre 2012 y 2014, la caída más importante en el consumo sucedió en el huevo San Juan en el quinto y el octavo decil. La variación de la demanda en el $\mathrm{V}$ decil fue de $-10.49 \%$ y en el VIII decil de $-11.25 \%$. La contracción de la demanda de huevo San Juan respondió tanto a la reducción del ingreso promedio trimestral de los hogares como al aumento de su precio promedio de $1.49 \%$. (Gráfica 7)

Cuadro 6

Demandas Marshallianas de huevo blanco en paquete de 12 piezas en México, 2012-2014 ${ }^{1}$

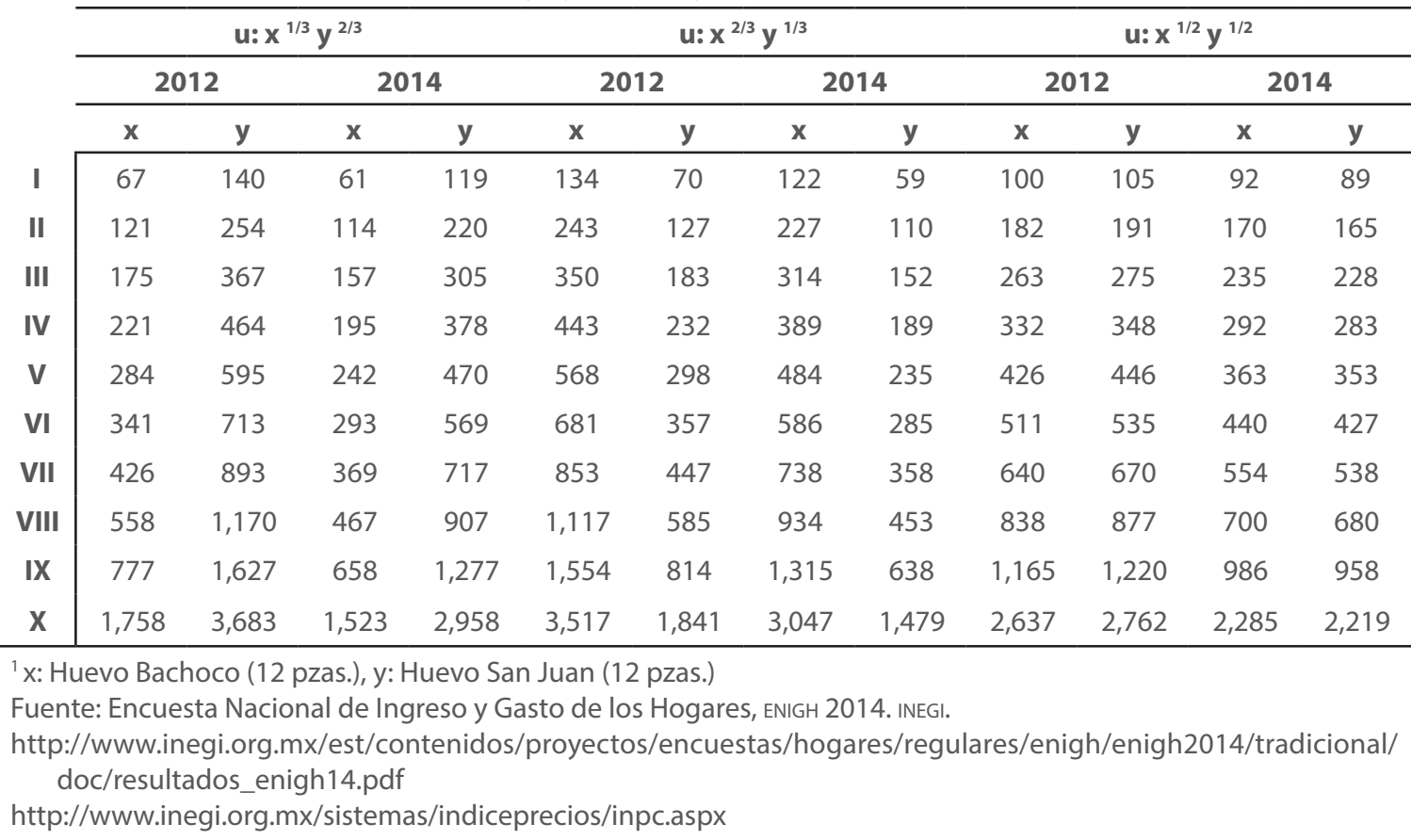

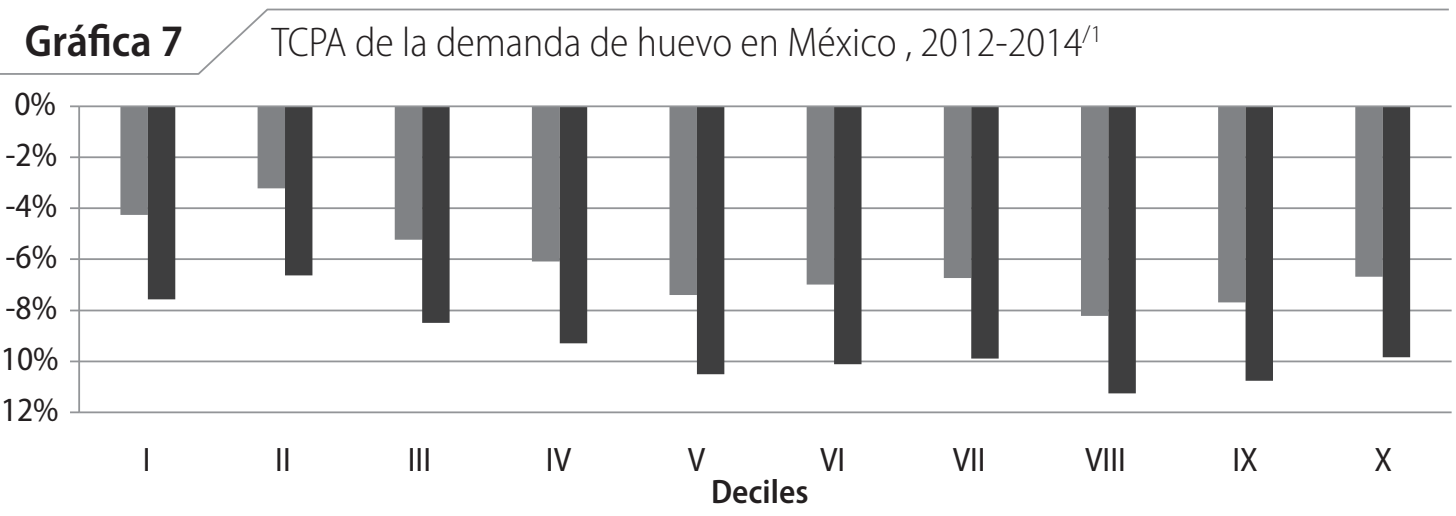

- Huevo Bachoco blanco, 12 pzas. - Huevo San Juan blanco, 12 pzas.

' Demanda de acuerdo con la función de utilidad $\mathrm{u}=\mathrm{x}^{1 / 2} \mathrm{y}^{1 / 2}$

Fuente: elaboración propia con base en http://www.inegi.org.mx/sistemas/indiceprecios/inpc.aspx 
Entre 2012 y 2014, el crecimiento del ingreso que presentaron los tres primeros deciles de hogares no impulsó el consumo de este bien básico, pero sí determinó una $\varepsilon_{Y}{ }^{D}$ negativa en estos tres deciles. En cambio, el cuarto decil font. Mientras que, en 2014, esta diferencia de consumo fue de 12602 y 5113 , respectivamente. (Cuadro 7)

* Entre 2012 y 2014, el crecimiento del ingreso que presentaron los tres primeros deciles de hogares determinó un ligero ascenso del

\section{Gráfica 8 Elasticidad ingreso de la demanda de huevo blanco en México, 2012-2014/1}

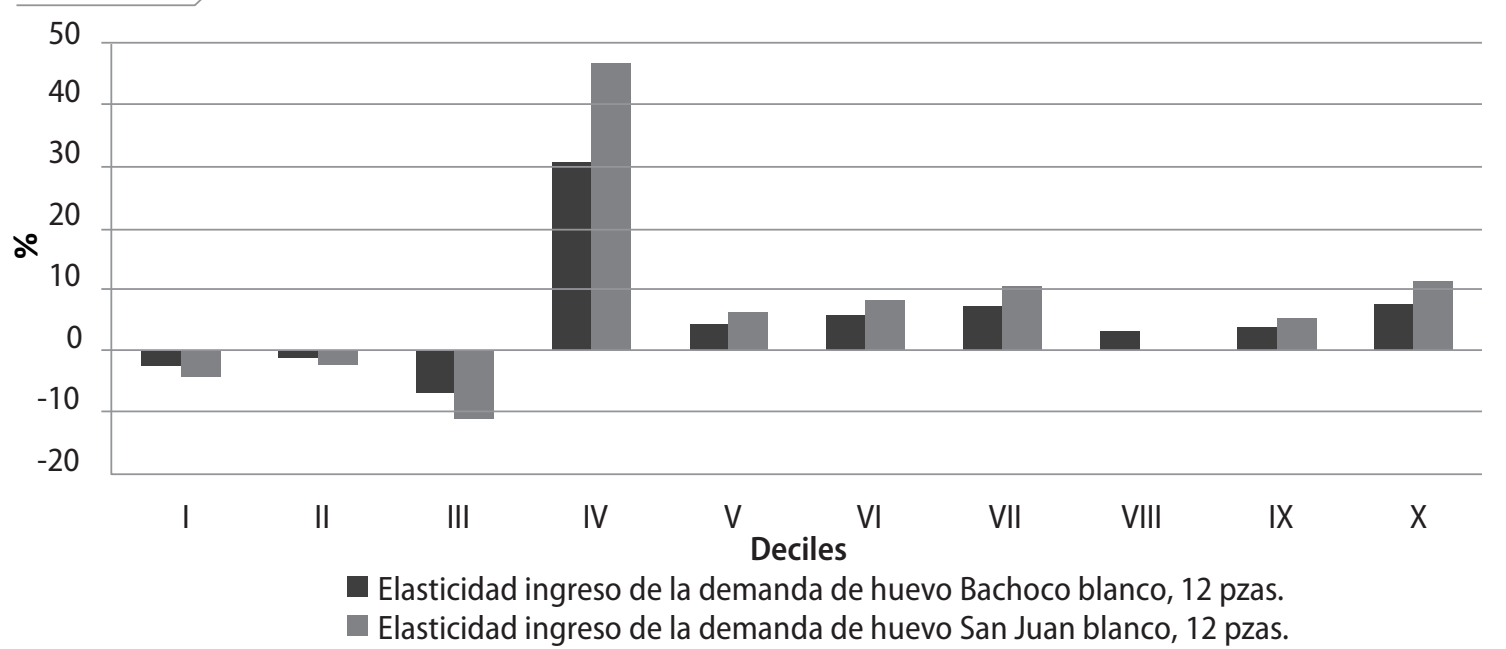

${ }^{1}$ Demanda de acuerdo con la función de utilidad $u=x^{1 / 2} y^{1 / 2}$

Fuente: elaboración propia con base en http://www.inegi.org.mx/sistemas/indiceprecios/inpc.aspx

fue el más afectado con una $\varepsilon_{Y}^{D}$ de $30.68 \%$ para el huevo Bachoco y $46.81 \%$ para el huevo San Juan. (Gráfica 8).

Finalmente, el quinto grupo de análisis (Agua Ciel y Agua Bonafont) difiere ligeramente del comportamiento de los grupos descritos (por ello se expone después del segundo, tercer, cuarto, y sexto grupos de análisis) en los siguientes elementos:

* La función $\left(u(x, y)=x^{2 / 3} y^{1 / 3}\right)$ determinó la mayor desigualdad en el consumo de botellas de 1.5 litros de agua. En 2012, según esta función existió una brecha en el consumo entre el primer y el decimo deciles de 12963 botellas de agua Ciel y 5860 botellas de agua Bona- consumo de agua Ciel, aunque el aumento fue significativo sólo para el segundo decil, con una TCPA de $2.61 \%$. La demanda de agua Ciel fue más sensible a los cambios en los precios y la de agua Bonafont resultó más sensible a las variaciones en el ingreso.

* La contracción de la demanda de agua más importante sucedió en el quinto y octavo deciles, destacando el descenso de la demanda de agua Bonafont, la cual respondió más a la reducción del ingreso que al aumento de su precio promedio de $5.29 \%$.

* El comportamiento de la $\varepsilon_{P}{ }^{D}$ del agua Ciel destacó porque la inflación promedio de su precio fue $6.39 \%$ menor respecto del agua Bonafont. 
Ximena Valentina Echenique Romero |

La desigualdad en México a partir de un modelo estadístico

idealizado de demandas Marshallianas, 2012-2014

Cuadro 7

Demandas Marshallianas de agua embotellada (1.5 LT) en México, 2012-20141

\begin{tabular}{|c|c|c|c|c|c|c|c|c|c|c|c|c|}
\hline & \multicolumn{4}{|c|}{$u: x^{1 / 3} y^{2 / 3}$} & \multicolumn{4}{|c|}{$u: x^{2 / 3} y^{1 / 3}$} & \multicolumn{4}{|c|}{$u: x^{1 / 2} y^{1 / 2}$} \\
\hline & \multicolumn{2}{|c|}{2012} & \multicolumn{2}{|c|}{2014} & \multicolumn{2}{|c|}{2012} & \multicolumn{2}{|c|}{2014} & \multicolumn{2}{|c|}{2012} & \multicolumn{2}{|c|}{2014} \\
\hline & $x$ & $y$ & $\mathbf{x}$ & $y$ & $\mathbf{x}$ & $y$ & $\mathbf{x}$ & $y$ & $\mathbf{x}$ & $y$ & $x$ & $y$ \\
\hline I & 256 & 463 & 264 & 428 & 512 & 232 & 527 & 214 & 384 & 347 & 395 & 321 \\
\hline II & 465 & 841 & 489 & 794 & 930 & 420 & 978 & 397 & 697 & 630 & 734 & 596 \\
\hline III & 671 & 1,213 & 676 & 1,097 & 1,342 & 607 & 1,351 & 548 & 1,006 & 910 & 1,013 & 823 \\
\hline IV & 849 & 1,535 & 838 & 1,361 & 1,698 & 767 & 1,677 & 680 & 1,273 & 1,151 & 1,258 & 1,021 \\
\hline V & 1,089 & 1,969 & 1,043 & 1,694 & 2,178 & 984 & 2,087 & 847 & 1,633 & 1,477 & 1,565 & 1,270 \\
\hline VI & 1,305 & 2,360 & 1,263 & 2,050 & 2,610 & 1,180 & 2,526 & 1,025 & 1,958 & 1,770 & 1,894 & 1,537 \\
\hline VII & 1,634 & 2,955 & 1,590 & 2,582 & 3,268 & 1,477 & 3,181 & 1,291 & 2,451 & 2,216 & 2,386 & 1,936 \\
\hline VIII & 2,140 & 3,870 & 2,011 & 3,265 & 4,280 & 1,935 & 4,023 & 1,632 & 3,210 & 2,902 & 3,017 & 2,449 \\
\hline IX & 2,977 & 5,382 & 2,833 & 4,599 & 5,953 & 2,691 & 5,667 & 2,299 & 4,465 & 4,037 & 4,250 & 3,449 \\
\hline X & 6,738 & 12,183 & 6,564 & 10,654 & 13,475 & 6,092 & 13,129 & 5,327 & 10,107 & 9,138 & 9,846 & 7,991 \\
\hline
\end{tabular}

${ }^{1} \mathrm{x}$ : Agua Ciel (1.5LT), y: Agua Bonafont (1.5 LT)

Fuente: Encuesta Nacional de Ingreso y Gasto de los Hogares, ENIGH 2014. INEGI.

http://www.inegi.org.mx/est/contenidos/proyectos/encuestas/hogares/regulares/enigh/enigh2014/tradicional/ doc/resultados_enigh14.pdf

http://www.inegi.org.mx/sistemas/indiceprecios/inpc.aspx

\subsection{Las demandas Marshallianas de servicios básicos en México}

Respecto al séptimo grupo de análisis (Especialista Médico General, EMG, y Especialista Médico General por Primera vez, EMGP) destaca el aumento de la desigualdad respecto a las consultas EMG, no obstante el descenso del precio de este servicio. También, sobresalieron los siguientes elementos:

${ }^{*}$ La función $\left(u(x, y)=x^{2 / 3} y^{1 / 3}\right)$ determinó la mayor desigualdad en el consumo de consultas médicas. En 2012, según esta función existió una brecha en el consumo entre el primer y el decimo decil de 220 consultas EMG y 183 consultas EMGP. Mientras que, en 2014, esta diferencia de consumo fue de 451 y 146, respectivamente. (Cuadro 8 )

* El segundo decil respondió de forma más elástica al descenso del precio de las consultas EMG, alcanzando una $\mathcal{E}_{P}{ }^{D}$ de $2.28 \%$ (Gráfica
9) y una TCPA de la demanda de $59.37 \%$ (Gráfica 10). El subgrupo de consultas EmGr fue impactado por las reducciones en el ingreso trimestral de los hogares y el incremento del precio, tanto que el séptimo decil alcanzó un descenso máximo de la demanda de $11.14 \%$ durante el periodo de estudio.

Finalmente, el octavo grupo de análisis de nuestra muestra (Química Sanguínea Completa, QSC, y Química Sanguínea de 6 elementos, QS6), se comportó como el segundo, tercer, cuarto y sexto grupo de bienes en el sentido que el consumo descendió en los diez deciles. Pero, las siguientes particularidades destacaron:

${ }^{*}$ La función $\left(u(x, y)=x^{1 / 3} y^{2 / 3}\right)$ determinó la mayor desigualdad en el consumo de consultas de química sanguínea. En 2012, según esta función existió una brecha en el consumo entre el primer y el decimo decil de 154 consul- 
Cuadro 8

Demandas Marshallianas de servicios de consultas médicas a especialista en México, 2012-20141

\begin{tabular}{|c|c|c|c|c|c|c|c|c|c|c|c|c|}
\hline & \multicolumn{4}{|c|}{$u: x^{1 / 3} y^{2 / 3}$} & \multicolumn{4}{|c|}{$u: x^{2 / 3} y^{1 / 3}$} & \multicolumn{4}{|c|}{$u: x^{1 / 2} y^{1 / 2}$} \\
\hline & \multicolumn{2}{|c|}{2012} & \multicolumn{2}{|c|}{2014} & \multicolumn{2}{|c|}{2012} & \multicolumn{2}{|c|}{2014} & \multicolumn{2}{|c|}{2012} & \multicolumn{2}{|c|}{2014} \\
\hline & $x$ & $y$ & $\mathbf{x}$ & y & $\mathbf{x}$ & $y$ & $\mathbf{x}$ & $y$ & $\mathbf{x}$ & y & $x$ & $y$ \\
\hline I & 4 & 14 & 9 & 12 & 9 & 7 & 19 & 6 & 7 & 11 & 14 & 9 \\
\hline II & 8 & 26 & 18 & 23 & 16 & 13 & 35 & 11 & 12 & 19 & 26 & 17 \\
\hline III & 11 & 38 & 24 & 31 & 23 & 19 & 48 & 16 & 17 & 28 & 36 & 24 \\
\hline IV & 14 & 48 & 30 & 39 & 29 & 24 & 60 & 19 & 22 & 36 & 45 & 29 \\
\hline $\mathbf{V}$ & 18 & 61 & 37 & 48 & 37 & 31 & 75 & 24 & 28 & 46 & 56 & 36 \\
\hline VI & 22 & 74 & 45 & 59 & 44 & 37 & 90 & 29 & 33 & 55 & 68 & 44 \\
\hline VII & 28 & 92 & 57 & 74 & 56 & 46 & 114 & 37 & 42 & 69 & 85 & 55 \\
\hline VIII & 36 & 121 & 72 & 93 & 73 & 60 & 144 & 47 & 55 & 90 & 108 & 70 \\
\hline IX & 51 & 168 & 101 & 132 & 101 & 84 & 203 & 66 & 76 & 126 & 152 & 99 \\
\hline$x$ & 114 & 379 & 235 & 305 & 229 & 190 & 470 & 152 & 172 & 284 & 352 & 229 \\
\hline
\end{tabular}

${ }^{1} \mathrm{x}$ : Consulta especialista médico general, y: Consulta especialista médico general por primera vez Fuente: Ibídem.

Gráfica 9 Elasticidad precio de la demanda de médicos especialistas en México, 2012-2014/1

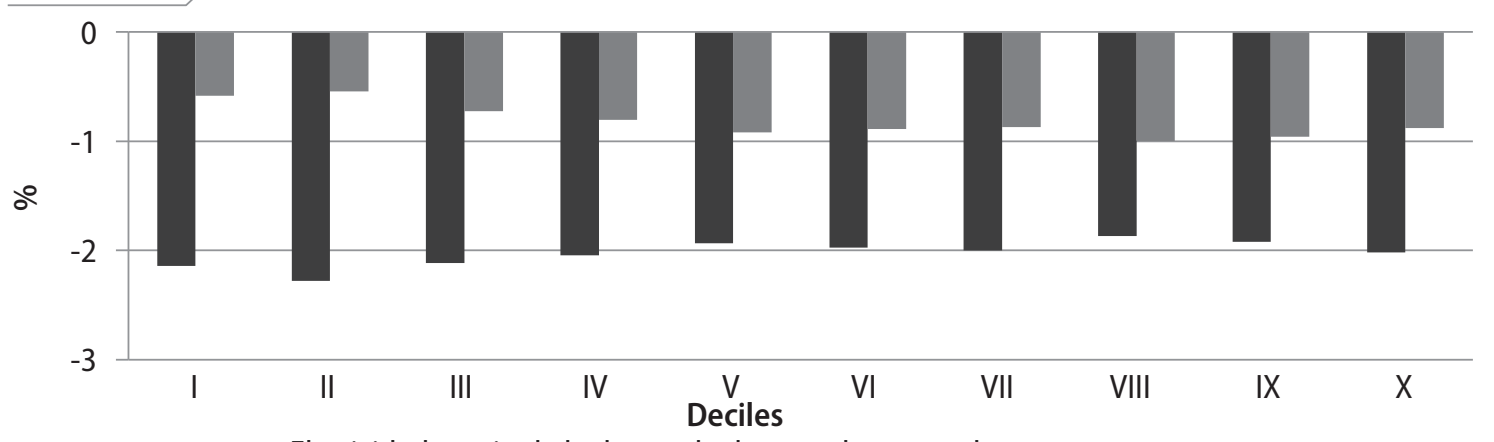

- Elasticidad precio de la demanda de consulta general.

- Elasticidad precio de la demanda de consulta general por primera vez.

${ }^{1}$ Demanda de acuerdo con la función de utilidad $u=x^{1 / 2} y^{1 / 2}$

Fuente: elaboración propia con base en http://www.inegi.org.mx/sistemas/indiceprecios/inpc.aspx

Gráfica 10 TCPA de la demanda de consulta a médico general en México, 2012-2014/1

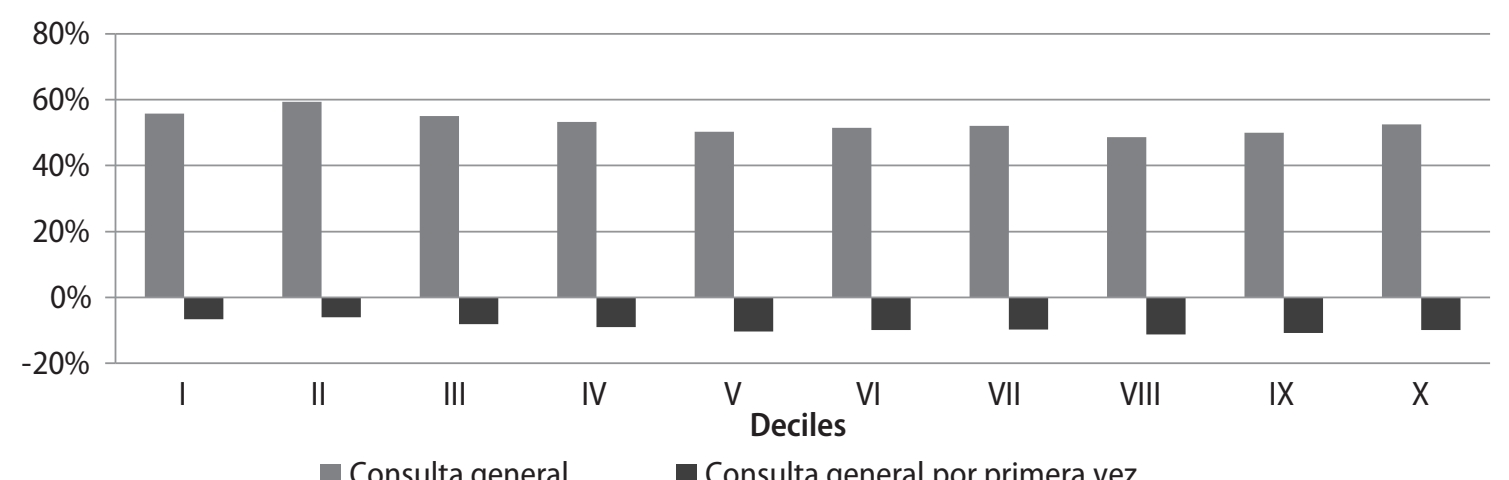

${ }^{1}$ Demanda de acuerdo con la función de utilidad $\mathrm{u}=\mathrm{x}^{1 / 2} \mathrm{y}^{1 / 2}$

Fuente: elaboración propia con base en http://www.inegi.org.mx/sistemas/indiceprecios/inpc.aspx 
Ximena Valentina Echenique Romero |

La desigualdad en México a partir de un modelo estadístico

idealizado de demandas Marshallianas, 2012-2014

Cuadro 9

Demandas Marshallianas de químicas sanguíneas en México, ${ }^{1}$ 2012-2014

\begin{tabular}{|c|c|c|c|c|c|c|c|c|c|c|c|c|}
\hline & \multicolumn{4}{|c|}{$u: x^{1 / 3} y^{2 / 3}$} & \multicolumn{4}{|c|}{$u: x^{2 / 3} y^{1 / 3}$} & \multicolumn{4}{|c|}{$u: x^{1 / 2} y^{1 / 2}$} \\
\hline & \multicolumn{2}{|c|}{2012} & \multicolumn{2}{|c|}{2014} & \multicolumn{2}{|c|}{2012} & \multicolumn{2}{|c|}{2014} & \multicolumn{2}{|c|}{2012} & \multicolumn{2}{|c|}{2014} \\
\hline & $x$ & $y$ & $x$ & $y$ & $x$ & $y$ & $x$ & $y$ & $\mathbf{x}$ & $y$ & $\mathbf{x}$ & $y$ \\
\hline I & 6 & 13 & 4 & 11 & 12 & 7 & 9 & 5 & 9 & 10 & 7 & 8 \\
\hline II & 11 & 24 & 8 & 20 & 22 & 12 & 16 & 10 & 17 & 18 & 12 & 15 \\
\hline III & 16 & 35 & 11 & 28 & 32 & 18 & 22 & 14 & 24 & 26 & 17 & 21 \\
\hline IV & 20 & 44 & 14 & 35 & 40 & 22 & 27 & 17 & 30 & 33 & 21 & 26 \\
\hline V & 26 & 57 & 17 & 43 & 52 & 28 & 34 & 22 & 39 & 43 & 26 & 33 \\
\hline VI & 31 & 68 & 21 & 53 & 62 & 34 & 41 & 26 & 47 & 51 & 31 & 39 \\
\hline VII & 39 & 85 & 26 & 66 & 78 & 43 & 52 & 33 & 58 & 64 & 39 & 50 \\
\hline VIII & 51 & 112 & 33 & 84 & 102 & 56 & 66 & 42 & 76 & 84 & 49 & 63 \\
\hline IX & 71 & 155 & 46 & 118 & 142 & 78 & 93 & 59 & 106 & 117 & 69 & 88 \\
\hline$x$ & 160 & 352 & 107 & 273 & 320 & 176 & 214 & 137 & 240 & 264 & 161 & 205 \\
\hline
\end{tabular}

${ }^{1} \mathrm{x}$ : Química sanguínea completa, y: Química Sanguínea de seis elementos.

Fuente: Encuesta Nacional de Ingreso y Gasto de los Hogares, ENIGH 2014. INEGI.

http://www.inegi.org.mx/est/contenidos/proyectos/encuestas/hogares/regulares/enigh/enigh2014/tradicional/ doc/resultados_enigh14.pdf

http://www.inegi.org.mx/sistemas/indiceprecios/inpc.aspx

tas QSC y 339 consultas QS6. Mientras que, en 2014, esta diferencia de consumo fue de 103 y 262, respectivamente. (Cuadro 9)

* En el octavo decil la contracción de la demanda de QsC fue de $17.69 \%$ y el descenso de QS6 elementos de $12.56 \%$. El comportamiento de la demanda del subgrupo QS6 respondió, particularmente, al aumento de su precio de $13.24 \%$; mientras que el efecto ingreso determinó el desempeño de la QSC, porque a su $\varepsilon_{P}^{D}$ fue inelástica.

\section{4.- La perspectiva de la desigualdad en México}

En los últimos años los valiosos estudios sobre la desigualdad y la pobreza en México han aumentado de forma significativa. Desafortunadamente, en este artículo únicamente es posible citar algunos de los que se vinculan en temas específicos del texto.

Fernando Cortés periodiza el problema de la desigualdad en México entre 1992-2000 y 2002-2006, concluyendo que durante estas dos fases los cambios significativos fueron en términos relativos y no absolutos. Porque la participación de los deciles superiores en el ingreso total disminuyó, mientras que la participación de los inferiores aumentó considerable- 
mente. ${ }^{17}$ De tal forma que "la desigualdad en la distribución del ingreso decreció a partir del año 2000". 18

No obstante, de acuerdo con Gerardo Esquivel, "la magnitud de la desigualdad en México es mayor de lo que era a principios de los ochenta", 19 aun cuando "resulta innegable una mejoraría en la distribución del ingreso entre los hogares que forman parte de la ENIGH" ${ }^{20}$

Además, de acuerdo con los cálculos de Miguel del Castillo, la magnitud de la desigualdad en México es mayor a la comúnmente estimada. ${ }^{21}$ Hecho que explica porque México es "el peor país en materia de desigualdad

17 “En efecto, cuando se pone la atención sobre las variaciones porcentuales que han experimentado las participaciones de los deciles se observa que: 1] los tres primeros deciles, los que incluyen a los hogares más pobres del país, gozaron de aumentos de 10 a $15 \%$ en su participación relativa, mientras que el décimo perdió 5\%; 2] los cambios favorecieron sistemáticamente a los deciles inferiores contra los superiores $y, 3]$ los aumentos o reducciones se ordenan de más a menos según la jerarquización de los deciles; la ganancia es mayor en los deciles inferiores y va decreciendo en la medida en que se pasa de los inferiores a los superiores; los deciles del extremo superior, el noveno y décimo, perdieron". Cortés, Fernando, Pobreza, desigualdad en la distribución del ingreso y el crecimiento económico, 1992-2006, en Cortés, Fernando y Orlandina de Oliveira (coord.) Los grandes problemas de México V desigualdad social, México, El Colegio de México, 2010, p. 74

18 Ibídem. p. 77.

19 Esquivel, Gerardo, Concentración del poder económico y político, México, oxfAM, Junio, 2015. pp.13

20 Ibídem.

21 Miguel del Castillo, quien ajusta el ingreso corriente total de los hogares de la ENIGH, presenta los siguientes resultados. “En 2012, el 10\% de los hogares más acaudalados concentró el $62 \%$ del ingreso total, mientras que el $1 \%$ más rico ganó, en promedio, 253 veces más que el $10 \%$ más pobre. El coeficiente de Gini se elevó en ese año al 0,68" (el dato oficial es de 0.45). Del Castillo, Miguel, La magnitud de la desigualdad en el ingreso y la riqueza en México, Serie Estudios y Perspectivas Núm. 167, México, CEPAL, 2015, p. 59. en el ingreso entre los miembros de la OCDE". 22 También, porque la nación "está dentro del $25 \%$ de los países con mayores niveles de desigualdad en el mundo". ${ }^{23}$

Nuestro análisis encontró dos elementos que se pueden asociar con los estudios antes referidos. 1) La mayor afectación en el consumo sobre los deciles medios y superiores de los hogares mexicanos (cuarto y octavo deciles particularmente) representa un hallazgo cercano con las conclusiones de Contreras (2010); 2) la contracción casi general del consumo de los bienes y servicios que integran nuestra muestra promueve compartir la preocupación de Esquivel respecto a la necesidad de una política de crecimiento en la que "la tendencia decreciente de la desigualdad -sea compatible-con otros aspectos por demás conocidos de la economía mexicana”. ${ }^{24}$

Entre las pretensiones de este artículo no se encuentran otorgar una lista de recomendaciones respecto a cómo reducir la desigualdad. Un tema que implicaría, como sugiere Atkinson, redefinir la visión economicista de la desigualdad y, como plantea Deaton, reflexionar la correlación directa entre el progreso y la desigualdad, y entre el modelo global de crecimiento y la desigualdad. En todo caso, la reflexión que pudiera derivarse de este estudio es que en México existe la tendencia decreciente de la demanda en la mayoría de los hogares debido a una contracción del ingreso real. Hecho que a largo plazo afecta los niveles de empleo, los salarios y la recaudación impositiva, determinantes directos del ingreso de los deciles inferiores y medios de los hogares.

\footnotetext{
22 lbídem.

23 Esquivel, Gerardo, op. cit. p. 12

24 Ibídem, p. 13
} 
Ximena Valentina Echenique Romero |

La desigualdad en México a partir de un modelo estadístico

idealizado de demandas Marshallianas, 2012-2014.

Una política económica dirigida a garantizar niveles dignos de alimentación, vivienda, salud y educación debe ser el pilar de una adecuada política económica nacional. Particularmente, de acuerdo con Francisco Villagómez, la política fiscal puede incidir en la igualdad a través del gasto público, los impuestos, los precios, los subsidios públicos, el déficit, la deuda y la política contra cíclica. (Tabla 1)
Las carencias de cobertura médica y alimentaria en productos cárnicos que resultó de nuestro estudio de demandas Marshallianas en México, entre otros elementos, nos llevan a respaldar las propuestas de Villagómez en materia fiscal: la discriminación del gasto social debe privilegiar a los grupos vulnerables para que el gobierno cumpla con el principio de no discriminación e igualdad. El gobierno debe

Tabla 1

Herramientas de política fiscal para promover la igualdad

\begin{tabular}{|c|c|}
\hline \multicolumn{2}{|r|}{ SALUd } \\
\hline Gasto público & Conveniencia de los programas de asistencia médica focalizados y universales. \\
\hline $\begin{array}{l}\text { Impuestos, precios y subsidios públi- } \\
\text { cos. }\end{array}$ & $\begin{array}{l}\text { Estructura impositiva a partir de los actores. } \\
\text { 1) Estimar la contribución al ingreso fiscal por los distintos grupos específicos de } \\
\text { población en función de su ingreso(deciles de ingreso). } \\
\text { 2) Analizar la estructura impositiva en impuestos directos(al ingreso)por grupos } \\
\text { específicos de la población. } \\
\text { 3) Calcular la incidencia impositiva de los impuestos indirectos entre distintos } \\
\text { grupos de la población. } \\
\text { 4) Revisar si la política de precios y subsidios en bienes y servicios públicos en } \\
\text { salud favorece a los grupos de menores ingresos. }\end{array}$ \\
\hline Déficit, deuda y política contra cíclica & $\begin{array}{l}\text { Analizar si durante recortes al gasto público, el gasto dirigido a los programas } \\
\text { sociales y los grupos de bajos ingresos se reduce. }\end{array}$ \\
\hline \multicolumn{2}{|r|}{ EMPLEO } \\
\hline Gasto público & $\begin{array}{l}\text { Estimar el monto de recursos y evolución para programas específicos de protec- } \\
\text { ción al empleo. }\end{array}$ \\
\hline $\begin{array}{l}\text { Impuestos, precios y subsidios } \\
\text { públicos }\end{array}$ & $\begin{array}{l}\text { Evaluar si las acciones fiscales han provocado mayor empleo temporal. } \\
\text { Relación entre acciones fiscales y empleo temporal }\end{array}$ \\
\hline \multicolumn{2}{|r|}{ Alimentación } \\
\hline Gasto público & $\begin{array}{l}\text { Examinar gasto público en programas de apoyo a la alimentación por diferentes } \\
\text { grupos sociales. }\end{array}$ \\
\hline & Analizar si los programas de apoyo a la alimentación son focalizados o universales. \\
\hline $\begin{array}{l}\text { Impuestos, precios y subsidios } \\
\text { públicos }\end{array}$ & $\begin{array}{l}\text { Analizar la contribución al ingreso fiscal por los distintos grupos en función de su } \\
\text { ingreso. }\end{array}$ \\
\hline Déficit, deuda y política contra cíclica & $\begin{array}{l}\text { Analizar la contribución al ingreso fiscal por los distintos grupos en función de su } \\
\text { ingreso } \\
\text { Evaluar si las acciones fiscales han provocado un mayor apoyo a la población en } \\
\text { pobreza alimentaria. }\end{array}$ \\
\hline
\end{tabular}

Fuente: elaboración propia con base en Villagómez, Francisco, El enfoque de la perspectiva de derechos en la política fiscal: construcción de un marco metodológico para aplicarse en México y países seleccionados de Centroamerica, México, CEPAL, 2014. pp. 50-63. 
maximizar los recursos fiscales para cumplir con los derechos económicos y sociales en los que debe habitar una sociedad justa. ${ }^{25}$

\section{5.- Conclusiones}

Esperamos haber cumplido con el interés de motivar a los alumnos de los primeros semestre de la carrera de Economía sobre la aplicación de uno de los conceptos más importantes de la Teoría Económica: las demandas Marshallianas. A partir de las cuales se pueden establecer indicadores respecto a un tema trascendental de la agenda nacional: la desigualdad. Misma que, desde una reflexión neoclásica-liberal, se puede definir con el siguiente enunciado: una distribución inequitativa del ingreso asociada a un problema de injusticia.

En el caso de México considerando las tres funciones de utilidad: $\left(u(x, y)=x^{1 / 3} y^{2 / 3}\right)$, $\left(u(x, y)=x^{2 / 3} y^{1 / 3}\right), y, \quad\left(u(x, y)=x^{1 / 2} y^{1 / 2}\right)$ observamos escenarios importantes durante 2012 y 2014. Primero, la brecha en el consumo entre el primer decil y el décimo decil sobre los grupos de bienes y servicios que se estudiaron descendió (con excepción de las consultas médicas con especialistas) debido a dos razones generales: el aumento de los precios de los bienes y los servicios implicados en el estudio (con excepción del huevo blanco Bachoco y las consultas médicas generales), y la reducción del ingreso a partir del cuarto decil de los hogares mexicanos. Segundo, el cuarto decil fue el sector de hogares más afectado en cuanto a consumo, tanto por el efecto ingreso (descenso del ingreso) como por el efecto precio (aumento de los precios). Tercero, suponiendo que un hogar

25 Villagómez, Francisco, El enfoque de la perspectiva de derechos en la política fiscal: construcción de un marco metodológico para aplicarse en México y países seleccionados de Centroamerica, México, CEPAL, 2014. pp. 50-63. promedio destinó la totalidad de su ingreso al consumo de cada bien y servicio estudiado encontramos las siguientes ocho aproximaciones:

1) Un hogar del primer decil podría consumir por semana un paquete $(500 \mathrm{~g})$ de leche Alpura y tres paquetes de leche Fortileche. Considerando una familia promedio de cuatro personas, el consumo per cápita de leche sería de $500 \mathrm{~g}$, esto siempre y cuando el ingreso se destinara a consumir leche. El segundo, tercero y cuarto deciles aún tendrían un consumo menor a cinco paquetes de leche Alpura. En el caso de la leche Fortileche, la condición es mejor a partir del segundo decil. Por su parte, una familia del décimo decil consumiría por semana 35 paquetes de leche Alpura y 87 paquetes de leche Fortileche.

2) Un hogar del primer decil podría consumir por semana $2 \mathrm{~kg}$ de Sirloin, pero no podría consumir siquiera $1 \mathrm{~kg}$ de filete en medallones. Considerando una familia de cuatro personas, el consumo per cápita sería $0.5 \mathrm{~kg}$ de Sirloin, esto siempre y cuando el ingreso se destine al consumo de carne. Esta situación no se mejora significativamente sino hasta el octavo decil, con un consumo promedio de $16 \mathrm{~kg}$ de Sirloin y $4 \mathrm{~kg}$ de filete en medallones. En cambio, una familia del décimo decil consumiría por semana $52 \mathrm{~kg}$ de Sirloin y $11 \mathrm{~kg}$ de filete en medallones; esto es, un consumo per cápita de 15.75 Kg por semana

3) El comportamiento del consumo en el caso de filete limpio y bistec bola es parecido al del Sirloin y filete en medallones. Un hogar del primer decil podría consumir por semana $2 \mathrm{~kg}$ de bistec bola pero su consumo de filete limpio no llegaría siquiera a $1 \mathrm{~kg}$. Esta situación no se mejora significativamente sino hasta el noveno decil, con un consumo promedio de $5 \mathrm{~kg}$ de filete limpio. En cambio, una familia del décimo decil consumiría por semana $56 \mathrm{~kg}$ de bistec bola y $11 \mathrm{~kg}$ de filete limpio. 


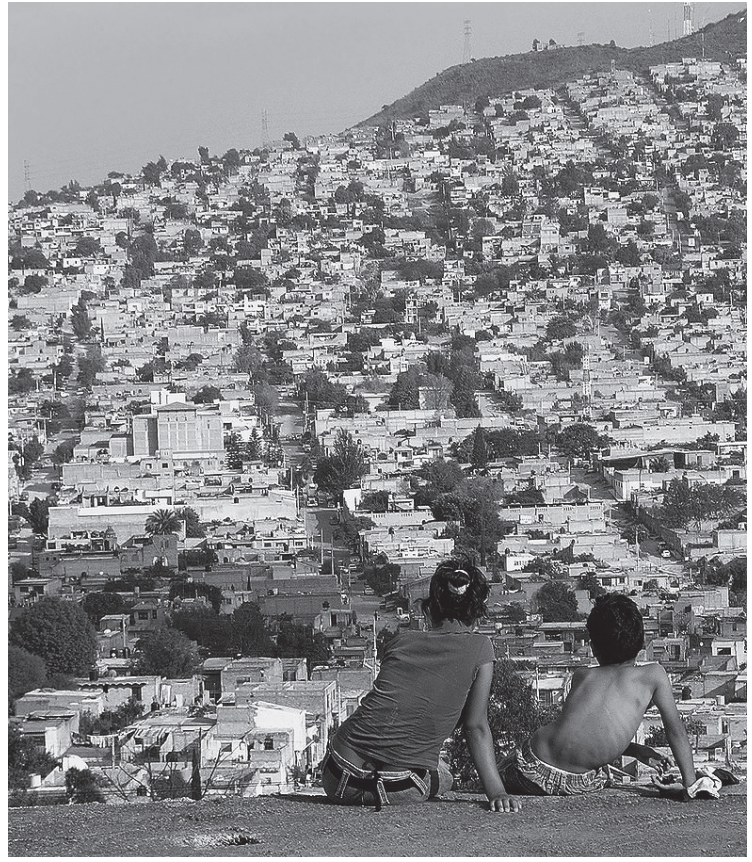

4) Un hogar del primer decil podría consumir por semana siete paquetes $(680 \mathrm{~g})$ de pan Bimbo y tres paquetes (680 g) de pan Wonder. Considerando una familia promedio de cuatro personas, el consumo per cápita de pan blanco sería de $1.7 \mathrm{~kg}$, siempre y cuando el ingreso se destinara a consumir pan blanco. En el caso de la marca Bimbo, desde el segundo decil el consumo superó la docena de unidades. Una familia del décimo decil consumiría por semana 170 paquetes de pan Bimbo y 75 paquetes de pan Wonder. El consumo per cápita por hogar sería de $41.65 \mathrm{~kg}$ semanales.

5) El agua podría ser un consumo "relativamente" garantizado en cada hogar, siempre y cuando éste no supere los 4 o 5 integrantes. Un hogar del primer decil podría consumir por semana 44 botellas (1.5 l) de agua Ciel y 18 botellas (1.5 l) de agua Bonafont. Es decir, considerando un hogar de 4 personas, cada persona podría consumir 23 litros de agua semanalmente si todo su ingreso lo destinará a comprar agua embotellada. La demanda aumenta considerablemente desde el segundo de- cil. El consumo por semana en litros del tercer y cuarto deciles de agua Ciel y agua Bonafont habría sido: 123 y 49.5, y 169 y 69, según decil y marca; mientras que una familia del décimo decil consumiría por semana 52 litros de agua Ciel y 130 litros de agua Bonafont. Es decir, un consumo per cápita por hogar de 182 litros semanales.

6) Un hogar del primer decil podría consumir por semana cinco paquetes (12 piezas) de huevo Bachoco y diez paquetes (12 piezas) de huevo San Juan. Considerando una familia promedio de cuatro personas, el consumo per cápita sería de 45 piezas de huevo, siempre y cuando el ingreso se destinará al consumo de huevo. El comportamiento de la demanda es similar al del agua: a partir del segundo decil el aumento en el consumo es considerable. Una familia del décimo decil consumiría por semana 127 paquetes de huevo Bachoco y 247 paquetes de huevo San Juan. Esto es, un consumo per cápita por hogar de 1,122 piezas de huevo semanales.

7) En el caso de las consultas a especialistas, no obstante el aumento de la oferta de "consultas de bajo costo" el acceso de la sociedad a este servicio médico resultó limitado. Un hogar del primer decil podría demandar por semana dos consultas generales y una consulta por primera vez. Es decir, si todos los elementos de la familia tuvieran alguna enfermedad durante la misma semana, uno de los integrantes no tendría acceso a una consulta privada. Esta situación mejora en el segundo decil, en el cual las cuatro personas que integrarían un hogar podrían asistir a una consulta general, destinando para ello la totalidad de su ingreso; mientras que una familia del décimo decil estaría en posibilidad de acudir por semana a 39 consultas generales y 13 consultas generales por primera vez, es decir, 13 consultas para cada integrante de la familia. 
8) Los análisis médicos sanguíneos también resultaron un servicio con baja cobertura social. Ningún integrante de un hogar del primer decil podría acceder durante una semana a un estudio de QS completa; únicamente podría realizarse un estudio de QS de 6 elementos. La cobertura del hogar se alcanzó hasta el cuarto decil, con un estudio de QS completa y tres análisis de QM de 6 elementos; mientras que una familia del décimo decil estaría en la posibilidad de demandar por semana 9 QS completa y 23 QS de 6 elementos, es decir, ocho químicas sanguíneas para cada integrante de la familia.

Los resultados expuestos sólo son aproximaciones que esperamos contribuyan, aunque sea un poco, al análisis de la desigualdad actual en México. Problemática que podría ser abordada por una adecuada política económica fundamentada en el principio de la justicia. Porque las políticas económicas contemporáneas, que han definido el actual modelo de crecimiento, parecen tener la limitante de "reducir" la desigualdad a través de la contracción del consumo. Particularmente, el consumo de los deciles medios de los hogares mexicanos.

El Estado a través de sus instituciones está obligado a generar políticas públicas con un alto valor público que garantice un nivel de vida digno y justo para la sociedad mexicana. $Y$ los economistas estamos obligados a debatir la visión economicista de las proporcionalidades sobre la distribución del ingreso y, sin duda, a mejorar las estimaciones sobre la desigualdad.

\section{Referencias}

Aristóteles, Política, Madrid, Gredos, 2008, pp. 45-63 y 279.

Atkinson, Anthony B, Desigualdad ¿Qué podemos hacer?, México, Fondo de Cultura Económica, 2015, pp. 25-153.
Cortés, Fernando, "Pobreza, desigualdad en la distribución del ingreso y el crecimiento económico", 1992-2006, en Cortés, Fernando y Orlandina de Oliveira (coord.). Los grandes problemas de México $\checkmark$ Desigualdad social, México, El Colegio de México, 2010. pp. 61-97.

Deaton, Angus, El Gran Escape Salud, riqueza y los origenes de la desigualdad, México, Fondo de Cultura Económica, 2015, pp. 28, 250.

Del Castillo, Miguel, "La magnitud de la desigualdad en el ingreso y la riqueza en México", Serie Estudios y Perspectivas Núm. 167, México, CEPAL, 2015, pp15-61, 79-81.

Dworkin, Ronald, Justicia para erizos, México, Fondo de Cultura Económica, 2014, pp. 428-442.

Esquivel, Gerardo, Concentración del poder económico y político, México, oxfam, Junio, 2015. pp. 11-16

Germa, Bel, "Estado ¿̨versus? Mercado”, en Estudios de Economía Aplicada, vol. 22, núm. 2, Madrid, Asociación de Economía Aplicada, 2004, pp. 231-249.

Gosepath, Stefan, "Equality", The Stanford Encyclopedia of Philosophy, Edward N. Zalta (ed.), 2011. http://plato.stanford.edu/archives/spr2011/entries/ equality/

Mas- Colell, Andreu, Michael Whinston y Jerry Green, Microeconomic Theory, New York, Oxford University Press, 1995, p. 15-51.

Piketty, Thomas, Capital in the Twenty-First Century, Londres, The Belknap Press of Harvard University Press, 2014, pp. 471- 514.

Rawls, John, A theory of justice, Estados Unidos, The Belknap Press of Harvard-University Press, 1994 (19ed), pp. 60-83.

Ronald, Dworkin, Sovereign virtue. The theory and practice of equality, Londres, Harvard University Press, 2000, pp. 109 - 139.

Varian, Hal R., Intermediate microeconomics: a modern approach, Nueva York, Norton \& Co, pp. 33-52.

Villagómez, Francisco El enfoque de la perspectiva de derechos en la politica fiscal: construcción de un marco metodológico para aplicarse en México y paises seleccionados de Centroamerica, México, CEPAL, 2014. pp. 50-63. 